Estudios sobre armas antiguas, arte militar $\mathrm{y}$ vida cultural en oriente y occidente

XXXVI (2016), pp. 7-31

ISSN: 0436-029X

doi: 10.3989/gladius.2016.0001

\title{
ESTUDIO METALÚRGICO DE LAS ARMAS IBÉRICAS HALLADAS EN EL VALLE DE JUTIA (NERPIO-YESTE, ALBACETE). TRABAJO, ARMAMENTO, RITUAL Y COMUNIDADES DE MONTAÑA ${ }^{1}$
}

\author{
METALLURGICAL STUDY OF THE IBERIAN WEAPONS FOUND \\ IN JUTIA VALLEY (NERPIO-YESTE, ALBACETE, SPAIN). WORK, \\ WEAPONRY, RITUALS AND MOUNTAIN COMMUNITIES
}

\author{
POR \\ Marc Gener Moret*, Damián Romero Perona**, \\ Susana González Reyero*** y Jorge García CARdiel ${ }^{* * * *}$
}

\section{RESUMEN - ABstract}

Presentamos un estudio metalúrgico de las armas de época ibérica documentadas en el valle de altura de Jutia (Nerpio-Yeste, Albacete) integrado en el análisis de su contexto arqueológico y en nuestra investigación en curso de las formas de organización de los paisajes de montaña durante la Edad del Hierro. Los resultados obtenidos son especialmente válidos en el caso de un soliferreum, cuyo análisis metalográfico nos permite caracterizar la tecnología del proceso de producción, y en el de una moharra de lanza, cuyo análisis plantea argumentos sobre la compleja vida social y las acciones sociales diversas que potencialmente contienen los objetos depositados en contextos rituales y funerarios.

We present a metallurgical study of weapons of the Iberian Iron Age documented in the high-altitude valley of Jutia (Nerpio-Yeste, Albacete, Spain) integrated in the analysis of their specific archaeological context and as part of our ongoing research about the forms of organization of mountain landscapes during the Iron Age. The results are

\footnotetext{
1 Este trabajo se ha realizado dentro de los proyectos de investigación destinados al análisis de la cuenca Alta del río Segura en época ibérica, dirigidos por el IH del CSIC y financiados por el MINECO (HAR2012-35208 y HAR201567355-P), así como por el financiado por el programa de investigación en Patrimonio Arqueológico y Paleontológico de Castilla-La Mancha 2014 (Formas de ocupación y organización territorial de áreas de sierra en época ibérica: el valle de Jutia (Yeste-Nerpio, Albacete). Los trabajos de prospección han sido debidamente autorizados por la Dirección General de Cultura, Consejería de Educación, Cultura y Deportes de la Junta de Castilla-La Mancha.

Deseamos agradecer a D. Plácido y a V. Balsera por su ayuda en lo concerniente a las fuentes clásicas y a las dataciones radiocarbónicas, respectivamente. Los trabajos de laboratorio asociados a este artículo se han llevado a cabo en los Laboratorios de Arqueometría de Materiales (LAM) y de Arqueología del Paisaje y Teledetección (LabTel) del Instituto de Historia (CCHS-CSIC).

${ }^{*}$ Departamento de Arqueología y procesos sociales, Instituto de Historia, Centro de Ciencias Humanas y Sociales, Consejo Superior de Investigaciones Científicas, Madrid, marc.gener@cchs.csic.es, http://orcid.org/0000-0002-4712-6183.

** Departamento de Arqueología y procesos sociales, Instituto de Historia, Centro de Ciencias Humanas y Sociales, Consejo Superior de Investigaciones Científicas, Madrid, damian.romero@cchs.csic.es, http://orcid.org/0000-0002-13041958.

*** Departamento de Arqueología y procesos sociales, Instituto de Historia, Centro de Ciencias Humanas y Sociales, Consejo Superior de Investigaciones Científicas, Madrid, susana.gonzalezreyero@cchs.csic.es, http://orcid.org/00000002-3887-6230.

**** Departamento de Historia Antigua, Facultad de Geografía e Historia, Universidad Complutense de Madrid, jgarciacardiel@ucm.es, http://orcid.org/0000-0002-1093-8129.
} 
especially valid in the case of a soliferreum, whose metallographic analysis allows us to characterize the technology of its production process, and a lance tip, whose analysis raises arguments about the complex social life and the various social actions potentially linked to the objects placed in ritual and funerary contexts.

Palabras Clave - Keywords

Iberos; Edad del Hierro; Sureste peninsular; Ocupación de áreas de montaña; Metalografía; Soliferreum; Armamento.

Iberians; Iron Age; Iberian Southeastern Plateau; Occupation of mountain areas; Metallography; Soliferreum; Weaponry.

\section{INTRODUCCIÓN Y OBJETIVOS}

La generalización del hierro en época ibérica constituye uno de los factores que coadyuvaron en los importantes cambios en la organización económica y en la estructura política y social que experimentaron los territorios de la fachada mediterránea y la parte meridional de la Península Ibérica durante la Segunda Edad del Hierro. Existe un acuerdo en reconocer que la incorporación de la metalurgia del hierro incidió significativamente en la transformación de los medios de producción, ya que la introducción de objetos de este metal permitió la optimización de numerosos procesos de trabajo, como facilitar la roturación de nuevas tierras (Cf., entre otros, Rovira Llorens, 1993; 2000; Rovira Hortalà, 1998; 2000; Chapa y Mayoral, 2007, 92; Mata et alii, 2009; Grau y Reig, 2002-2003; González et alii, 2015). Así, y en parte gracias a la generalización del uso del hierro, se habría producido en época ibérica una intensificación productiva que conllevaría la generación de excedentes potencialmente comercializables. En el estado actual de conocimientos se puede subrayar, por tanto, la relación entre la generalización del hierro y las formas de producción y de complejidad social propias de las sociedades iberas.

A pesar de esta importancia del hierro en época ibérica, lo cierto es que existen numerosos aspectos insuficientemente conocidos que nos impiden caracterizar mejor su repercusión en las formas de producción y de complejidad social iberas ya aludidas. Entre otros, sigue siendo necesario incidir en la caracterización de los procesos tecnológicos y su variabilidad a lo largo del tiempo ibérico, así como identificar y comparar las producciones de los diversos territorios como forma de valorar, entre otros, los grados de homogeneidad-diversidad y continuismoinnovación.

Dentro de esta línea de trabajo, presentamos un análisis de la metalurgia utilizada en época ibérica en un área del interior del sureste peninsular, concretamente en el valle de altura de Jutia (Nerpio-Yeste, Albacete). En concreto presentamos los datos correspondientes a un conjunto de piezas recuperadas durante la investigación arqueológica del valle citado que, mayoritariamente, pueden relacionarse con armamento o herramientas de corte.

El armamento de época ibérica ha sido objeto de amplias y bien conocidas investigacio$n^{2}{ }^{2}$ que nos han permitido conocer mejor este tipo de registro, de indudable importancia en nuestra interpretación de la organización social en época ibérica. En este sentido, la presencia de armamento se interpreta habitualmente como uno de los elementos que indicarían cómo se gestiona socialmente la conflictividad y cómo la producción y posesión de determinados objetos fue utilizada por determinados grupos sociales para construir la desigualdad e imponer

2 Por citar solamente algunos textos de las dos últimas décadas, cf. Quesada, 1997; 1998; 2002 a; 2002-2003; 2004; 2005; 2009; 2010a; Pérez Daza, 2003; Farnié y Quesada, 2005; García Jiménez, 2011. Para una revisión de conjunto actualizada de la arqueología militar prerromana, cf. Quesada, 2014. 
una determinada visión de la realidad. La exhibición y potencial uso del armamento incide, sin duda, en la construcción de un determinado tipo de persona social, que se expone y se recuerda especialmente en ciertos lugares como las necrópolis y los santuarios. Esta fuerte faceta socio-cultural del armamento alimenta el debate sobre el peso específico de su aspecto ritual y social, siendo no obstante escasos los estudios enfocados a la perspectiva tecnológica y funcional publicados hasta la fecha ${ }^{3}$.

Por otro lado, existe una notable escasez de publicaciones que traten sobre estudios metalúrgicos de armamento ibérico, y lo que hay publicado adolece de falta de sistematicidad, además de deberse a momentos diferentes de la investigación que han motivado una heterogeneidad de objetivos y métodos. Esta situación es extensible de forma general a la tecnología del hierro en el mismo contexto, lo cual dificulta la construcción de una visión global del entorno tecnológico y sus implicaciones sociales, especialmente en lo referente a las armas como instrumentos y símbolos de la violencia. Se trata de una realidad denunciada desde hace tiempo ${ }^{4}$ que necesita abordarse con planificación y rigor, pero que sobre todo requiere contribuciones multidisciplinares que integren los aspectos arqueológicos y analíticos del problema, con el fin de extraer el máximo de información significativa de cada intervención, desde los datos analíticos y la metodología de la intervención, hasta la sistematización de sus resultados y su valoración social en un contexto temporal y espacial preciso.

\section{LOS PAISAJES DE MONTAÑA DURANTE LA EDAD DEL HIERRO: EL VALLE DE JUTIA (YESTE-NERPIO, ALBACETE)}

Desde el Instituto de Historia del Consejo Superior de Investigaciones Científicas estamos llevando a cabo una línea de investigación dirigida a analizar las formas de ocupación y explotación del territorio en paisajes de montaña durante la Edad del Hierro. Nuestra investigación se centra en la cuenca alta del río Segura, un espacio ubicado entre las Comunidades Autónomas de Castilla-La Mancha, Murcia y Andalucía. Este territorio presenta gran interés al constituir una zona poco estudiada, un amplio espacio intermedio entre regiones mejor definidas del mundo ibérico como son el Sureste, la Submeseta Sur y el Alto Guadalquivir.

Dentro del dominio geomorfológico de los sistemas béticos, la cuenca alta del río Segura se caracteriza por una orografía marcada, en ocasiones abrupta, donde se intercalan pequeños valles longitudinales que concentran los cultivos. Es un territorio que presenta grandes desniveles, con alturas que habitualmente superan $\operatorname{los} 1.000 \mathrm{~m} \mathrm{~s}$. n. m. de altitud y llegan en ocasiones a los $2.000 \mathrm{~ms}$. n. m. Se trata, por tanto, de una de las áreas más altas del Sureste de la Península Ibérica y de Castilla-La Mancha. Características destacadas de este sector de los sistemas béticos son, por tanto, su marcada compartimentación territorial, resultante de su geomorfología y, también, su gran diversidad y riqueza medioambiental. Encontramos un clima propio del piso de vegetación supramediterráneo, con una cobertura vegetal variable en función de las particularidades orográficas de cada zona y con corrientes fluviales que encajan en los ejes tectónicos y que se convierten en pasos naturales de fauna y de población desde la Prehistoria. Abundan los recursos naturales, que ayudan a explicar un poblamiento antiguo del que es testimonio, por ejemplo, el abundante arte rupestre prehistórico, integrado en el Con-

\footnotetext{
3 Véase por ejemplo, para la Edad de Bronce, una primera aproximación en Kristiansen, 2002 y para estudios más específicos Molloy, 2008, 2009 y 2011; Mödlinger, 2010, 2012 y 2013 o Gener, en prensa. Para la Edad del Hierro en el contexto peninsular, véase Quesada 2014; Gener y Montero, en prensa.

4 Véase por ejemplo Quesada, 2002b: 20-24; Rovira, 2004: 80-82; o, más específicamente para el caso del armamento Quesada, 2010-2012 y Gener y Montero, en prensa.
} 
junto de Arte Rupestre del Arco Mediterráneo de la Península Ibérica incluido por la UNESCO en la Lista del Patrimonio Mundial en 1998.

En época ibérica, y aunque no es un territorio inmediato a las principales vías de comunicación que conocemos entre la costa mediterránea y el interior, subrayamos también cómo discurren ciertas vías de paso naturales. Se ha señalado especialmente la de Yeste y Elche de la Sierra, que conectaba el área de Cástulo con las costas mediterráneas de la Península Ibérica, siguiendo para ello un itinerario más accidentado que el de los Llanos centrales de Albacete (Sanz, 1997; López et alii, 1992: 59-60; Soria, 2000: 41).

Nuestro análisis del Alto Segura tiene como objetivo el estudio de los patrones de asentamiento, la organización territorial y su legitimación ideológica desde una lectura diacrónica. En este artículo nos centramos en los materiales procedentes de las prospecciones y excavaciones que estamos llevando a cabo en el valle de Jutia. Ubicado en el sector septentrional de las Cordilleras Béticas, Jutia es un valle de orientación suroeste-noroeste, representativo de los espacios abiertos de la Sierra de Segura. Con una altitud entre los 1280 y los $1550 \mathrm{~m} \mathrm{s.} \mathrm{n}$. m. y unas 1650 hectáreas de extensión aproximada, el valle está rodeado de una serie de elevaciones de formaciones calizas con intercalaciones de areniscas y de conglomerados, como la sierra de Góntar al oeste y la Cuerda de la Torca del Agujero por el este, que delimitan su perímetro salvo por el noreste. El fondo del valle de Jutia es un amplio espacio de tierras arables

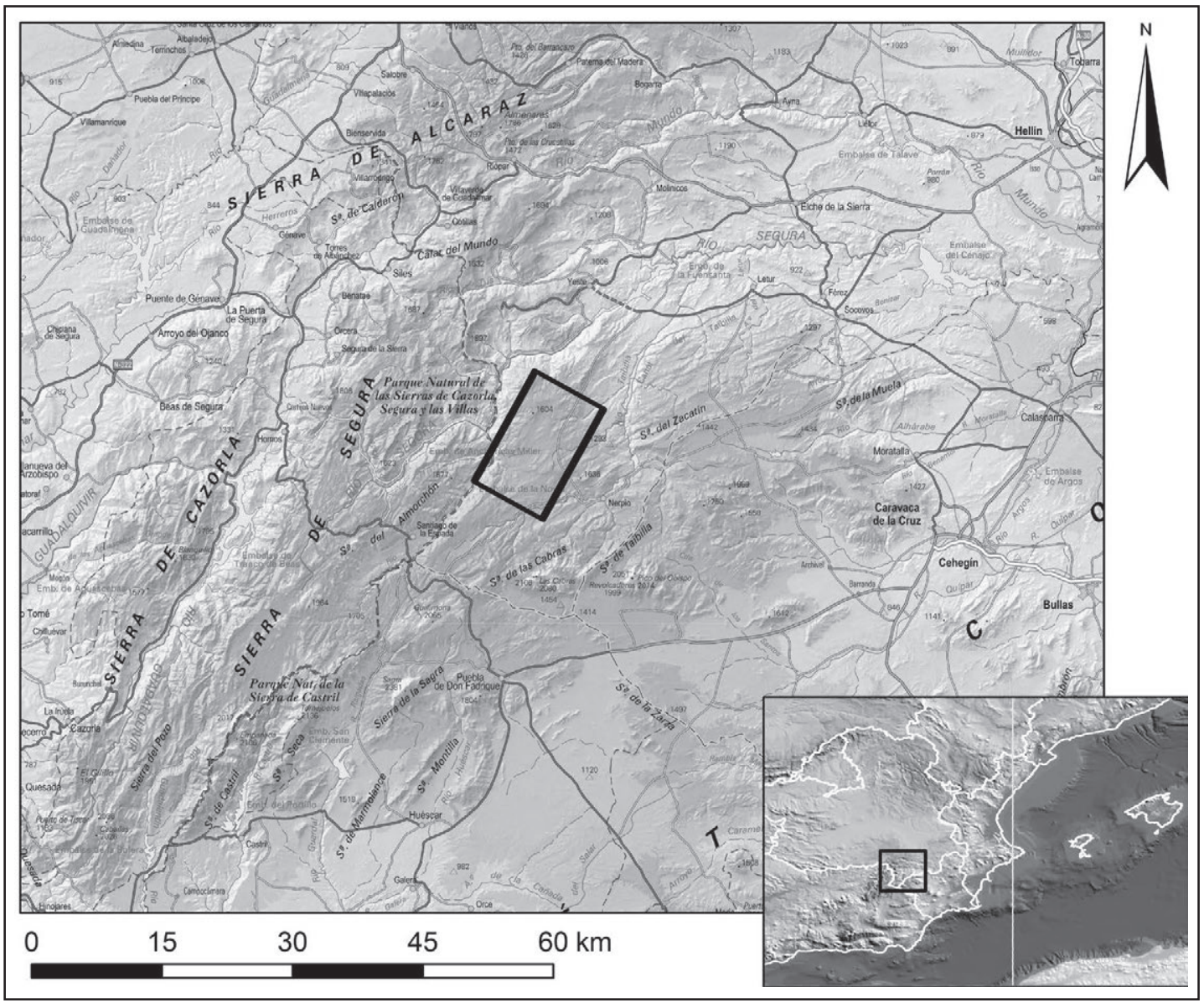

Figura 1. Localización del valle de Jutia (Yeste-Nerpio, Albacete). 
de alta capacidad de uso, con un claro predominio de las zonas llanas o con suave pendiente. Además, son frecuentes los manantiales o fuentes que configuran varios cauces de agua. El principal, el arroyo de Rivelte, desagua al oeste, en dirección al río Zumeta.

Estas características geográficas y ambientales del valle de Jutia lo configuran como un escenario idóneo para un análisis destinado a evaluar la organización de este tipo de espacios de altura por parte de las comunidades iberas, un tema relevante e insuficientemente conocido que estamos abordando en la actualidad. Además, los restos escultóricos ya conocidos de este valle (Chapa, 2007-08) confirman la ocupación o frecuentación del valle en época ibérica y la idoneidad de llevar a cabo una actuación interdisciplinar en este espacio en altura, que puede ser representativo de los espacios de sierra de los sistemas béticos.

\section{METODOLOGÍA}

\section{A. EXCAVACIÓN, PROSPECCIÓN Y SELECCIÓN DE LAS PIEZAS}

Nuestra actuación en el valle de altura de Jutia parte de la convergencia de disciplinas y metodologías en una visión complementaria que integra, a su vez, diferentes escalas de análisis. Entre las actuaciones que estamos llevando a cabo mencionamos por su relación con la temática abordada aquí el estudio del poblamiento y de los usos antiguos del valle, con actuaciones que van desde la fotointerpretación a través de varios vuelos aéreos a la prospección selectiva, al estudio de los espacios agrarios y al análisis de secuencias palinológicas y medioambientales, así como una actuación arqueológica en el entorno del monumento escultórico de Jutia. De las diferentes actuaciones realizadas vamos a destacar las intervenciones arqueológicas de prospección y excavación ya que son las que han permitido obtener el registro arqueológico que analizamos en este trabajo.

Del poblamiento antiguo del valle nos interesa ahora destacar dos yacimientos de la Edad del Hierro. El primero de ellos, el Cerro de Jutia, es un asentamiento situado a poco más de 50 metros al norte del cortijo homónimo actual. Se trata de un pequeño teso con forma relativamente circular que le otorga un afloramiento de roca, morfología que no parece que fuese la original sino el resultado de las diferentes transformaciones que ha experimentado el área desde los años 50 del siglo XX. Así, la comparación de su morfología actual con una serie de vuelos históricos (las dos series del vuelo americano) nos permite subrayar las transformaciones que ha experimentado su orografía. En superficie son visibles algunas alineaciones de piedra, así como materiales que sitúan el yacimiento entre el Ibérico pleno y época republicana. La construcción de un depósito en su parte superior y la fuerte erosión que parece haber sufrido, junto al uso de maquinaria agrícola moderna, han alterado notablemente el yacimiento.

La segunda zona de trabajo, Jutia, se encuentra a unos 650 metros al noreste del anterior. En esta zona, los trabajos llevados a cabo desde 2010 nos han permitido relacionar las esculturas ibéricas ya conocidas (Chapa, 2007-08) con una zona del fondo del valle donde hemos planteado una actuación arqueológica en la que convergen la prospección intensiva, la prospección geofísica y la excavación como forma de caracterizar las acciones sociales que definen este espacio ritual ibérico (González Reyero, 2013; González Reyero et alii 2015; e. p.; García Cardiel, 2015). Tras esta fase, se ha podido documentar un momento de ocupación tardoantigua, posiblemente encuadrable entre los siglos IV y V d. n. e. A estas dos fases se le suma una explotación agropecuaria de tipo tradicional que se concreta en el cortijo del Álamo, abandonado en los años 60 del siglo XX. En las últimas décadas, y tal y como pasó en el Cerro de Jutia, la zona sufrió una transformación agrícola que ha alterado la morfología y parte de 
los restos arqueológicos. La fotointerpretación, no obstante, ha posibilitado documentar parte de estos restos y plantear los posteriores trabajos de prospección intensiva, geofísica y excavación.

Esta necesidad de caracterizar una amplia extensión en torno a Jutia motivó el planteamiento de una prospección intensiva con el doble objetivo de delimitar el área de actividad antrópica y establecer, en lo posible, áreas con diferencias cronológicas y/o funcionales. Para ello se realizó una prospección con detector de metales que permitiera situar todas las anomalías metálicas, recuperando los elementos superficiales, esto es, aquellos situados entre 0 y 10 centímetros. Consideramos oportuno precisar que, aunque tradicionalmente los detectores de metales se relacionan con el expolio de yacimientos, por lo que algunas comunidades autónomas han recogido en sus Leyes de Patrimonio apartados específicos sobre este tipo de instrumentos, circunscribiendo su uso (Art. 50 de la Ley 4/2013 de 16 de mayo, de Patrimonio Cultural de Castilla-La Mancha), sin embargo, en los últimos años su uso se ha ido incorporando en diferentes proyectos arqueológicos, tanto en fases de prospección (se puede destacar su uso en campos de batalla como Baecula en Santo Tomé (Jaén) o Kalkriese (Baja Sajonia), así como los campamentos romanos de La Carisa entre Aller y Lena (Asturias), A Recacha entre Navia de Suarna (Lugo) e Ibias (Asturias) y A Granda das Xarras entre Ibias (Asturias) y Candín (León) como en excavación (Fernández Flores, 1999; 2003; Noguera et alii, 2015) por los

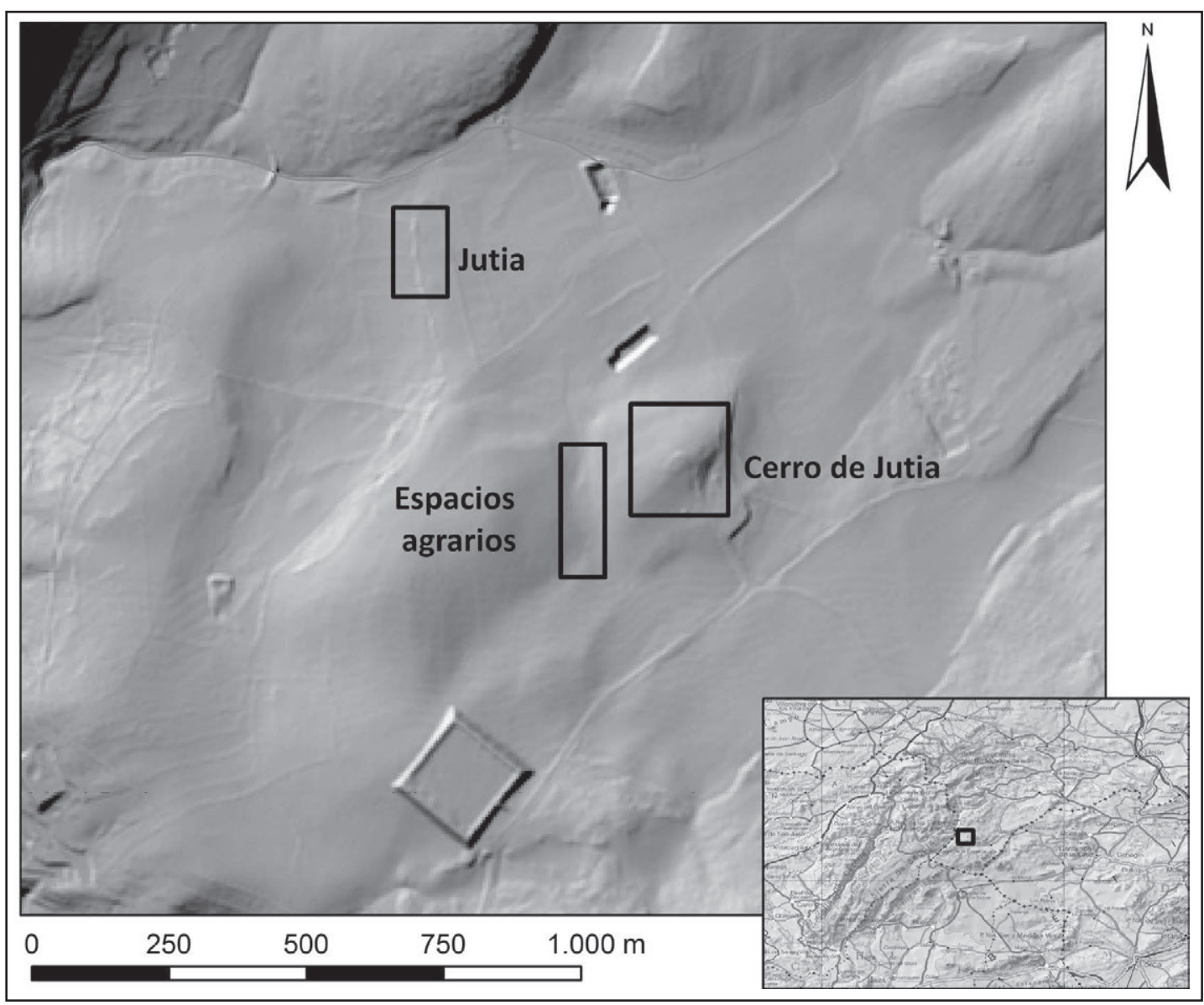

Figura 2. Localización de las diversas áreas arqueológicas estudiadas en el valle de Jutia. 
beneficios indudables que ofrece cuando se utiliza en el marco de proyectos de investigación con objetivos y marcos de actuación bien definidos.

En nuestro caso, el detector de metales se utilizó en un área alterada por la introducción de maquinaría agrícola y del arado de vertedera, que llega a profundidades de más de 30 centímetros, lo que había afectado parte de los niveles arqueológicos. La recuperación de objetos, que tan solo se practicó en casos específicos, se realizó por tanto sobre materiales removidos y nunca afectando a unidades estratigráficas. Los resultados han permitido definir de forma más exacta las dimensiones, distribuciones, áreas de actividad así como procesos postdeposicionales del área, y actualmente se está procediendo al análisis en conjunto con los datos de la fotointerpretación y la prospección geofísica. Durante los trabajos se recuperaron 29 piezas de un total de 153 anomalías detectadas. De esas 29 algunas correspondían a objetos modernos, con una gran mayoría de clavos de forja de compleja adscripción cronológica, y una serie de piezas que pertenecerían tanto a la Edad del Hierro como a época tardoantigua. De éstas se seleccionaron dos cuyas características eran claramente ibéricas y que analizamos en los apartados siguientes, un fragmento de falcata y un fragmento irregular de hierro, muy alterado y oxidado, que corresponde a la hoja de algún tipo de arma o herramienta de corte.

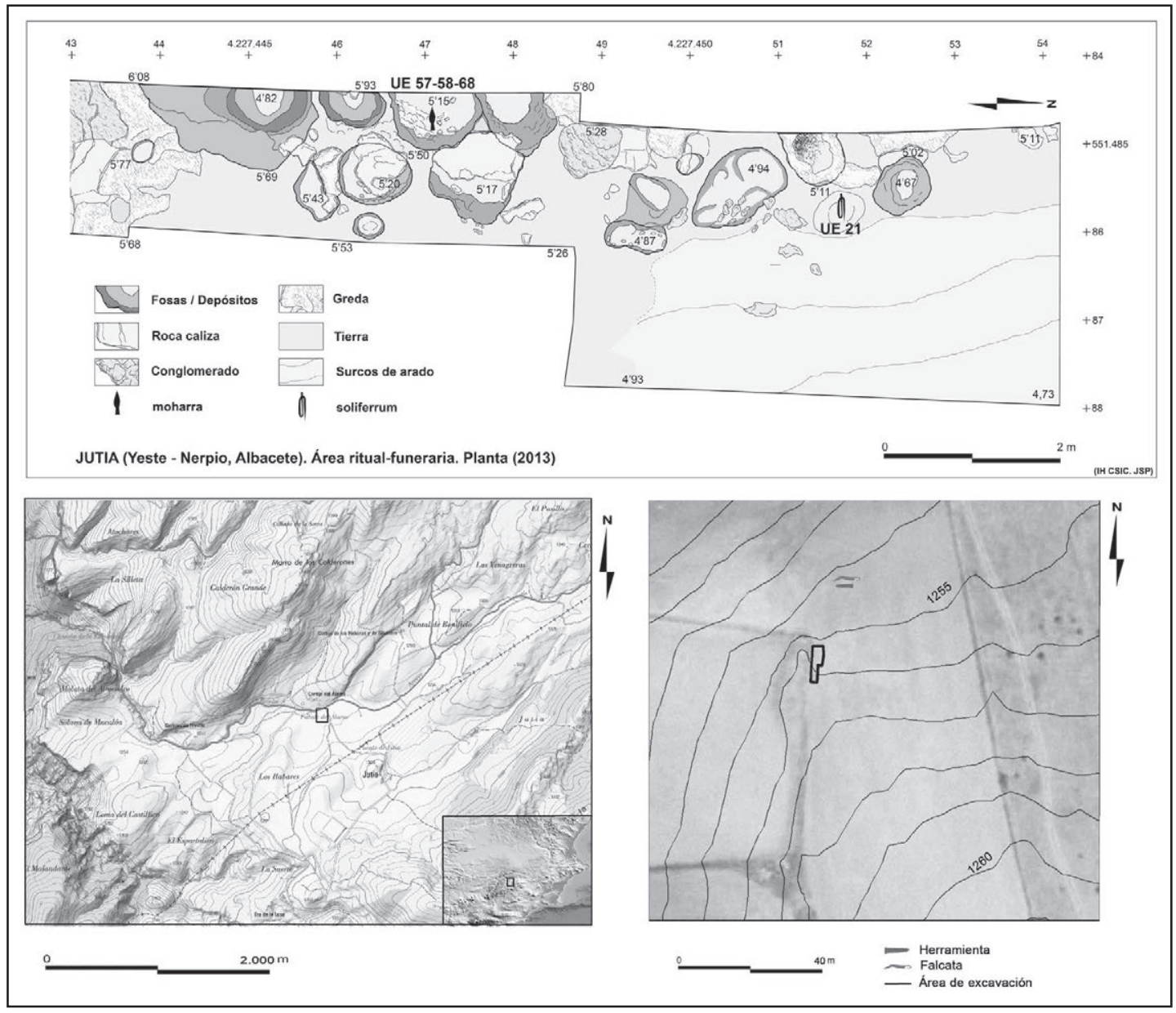

Figura 3. Ubicación de los materiales metalúrgicos analizados en las áreas de prospección y excavación del valle de Jutia (Yeste-Nerpio, Albacete). Instituto de Historia-CSIC, fuentes cartográficas: CNIG. 
Vamos a referirnos a la excavación planteada en el área ritual de Jutia desde 2013, de donde proceden el resto de materiales que vamos a analizar aquí. Sin duda, la posibilidad de investigar el entorno y el contexto de un monumento de época ibérica que conlleva elementos constructivos y escultóricos reviste un especial interés científico. Por este motivo, la prospección geofísica e intensiva llevada a cabo en esta zona se ha completado con varios sondeos, configurando así una serie de actuaciones interrelacionadas como base para nuestra aproximación a los usos sociales de este espacio.

Los sondeos se han diseñado para intentar responder a varias cuestiones o hipótesis de partida. Por una parte, era fundamental ubicar y definir las actividades de época ibérica que constatábamos mediante la prospección. Esta cuestión nos llevó también a documentar el grado de arrasamiento y la inversión estratigráfica provocada en algunos sectores por la acción del arado de vertedera. Igualmente, hemos procurado que nuestra intervención no se restringiese estrictamente al monumento, por lo que el diseño de la actuación arqueológica ha priorizado también conocer su entorno y contexto espacial. Para ello hemos intervenido en este entorno del área monumental ibérica mediante un amplio sondeo que nos ha permitido obtener datos sobre la orografía antigua, así como una secuencia paleoambiental que permite caracterizar la transición entre una zona de humedal y el área ritual ibérica además de procurarnos datos polínicos y paleoambientales para el valle (González Reyero, 2013; González Reyero et alii, 2015).

\section{B. ANÁlisis METALOGRÁFicos}

Hemos procedido a analizar los objetos metálicos más significativos de la campaña de 2013 desde un punto de vista científico con el fin de determinar su composición y su tecnología de fabricación, obteniendo así elementos para formarnos un criterio a la hora de determinar su función. Las zonas de pulido y muestreo se han elegido teniendo en cuenta tanto las posibilidades patrimoniales y expositivas de los objetos, limitadas en este caso por la escasa entidad de los fragmentos, como su potencial información científica, que parece notable ante la escasez tradicional de estos estudios. A su vez, consideramos que la obtención de información tecnológica es la vía para poder arbitrar medidas adecuadas de conservación, exposición y divulgación para el armamento de esta época.

Al tratarse de objetos de hierro y muy afectados por la corrosión, la técnica más adecuada para obtener la información que nos interesa es el análisis metalográfico. Para ello, se extrajeron muestras de los objetos mediante una sierra rotativa de diamante de baja velocidad de manera que las partes potencialmente más significativas desde un punto de vista tecnológico quedaran al descubierto. A continuación se embutieron los fragmentos o las piezas en resina bicomponente de fraguado rápido de manera que la parte que se quería estudiar quedara expuesta. La probeta resultante se lijó y pulió cuidadosamente, con mínima pérdida de masa, hasta conseguir un acabado especular, siguiendo los protocolos habituales en la preparación de muestras metalográficas (Rovira y Gómez Ramos, 2003; Scott, 1991). Una vez obtenida una superficie metálica homogénea, se aplicó por inmersión un reactivo químico frente al que los diferentes elementos de la microestructura reaccionan de manera particular, creando así un contraste y permitiendo distinguirlos mediante observación microscópica. En este caso los reactivos aplicados fueron picral (ácido pícrico en solución alcohólica) al 4\% seguido de nital (ácido nítrico en solución alcohólica) al 2\%. Tras neutralizar los reactivos para detener el ataque químico, se observó el resultado mediante un microscopio óptico LEICA DMLM con capacidad de entre 50 y 1000 aumentos, que incorpora una cámara digital LEICA DFC480. 
Las concentraciones de carbono se presentan en todos los casos como \% en peso. Finalizado el análisis, está prevista la restauración de las piezas afectadas.

\section{MATERIALES ANALIZADOS}

Los materiales de hierro que analizamos en este trabajo proceden del contexto arqueológico ya anunciado de Jutia, caracterizado por una serie de actividades sociales realizadas en época ibérica en torno a un monumento que se dotó de un trabajo escultórico.

Las actuaciones arqueológicas convergentes planeadas para dicho espacio, desde la fotointerpretación, a la prospección intensiva, la prospección geofísica y la excavación, han permitido circunscribir y caracterizar el lugar donde se llevó a cabo esta monumentalización arquitectónica y escultórica en época ibérica, a juzgar por las esculturas ya mencionadas y por los nuevos elementos arquitectónicos recuperados en nuestros trabajos (entre ellos, un bloque con grapa en T).

Por el indudable interés científico que adquiere la caracterización de estos espacios, y pese a tratarse de un estudio en curso, vamos a referirnos sucintamente a los contextos relacionados antes de entrar en el análisis metalúrgico propiamente dicho. El contexto arqueológico consiste en una serie de depósitos que rellenan estructuras negativas de diversa morfología y profundidad, ubicadas en un afloramiento rocoso que se eleva ligeramente en el entorno. Mientras que en los estratos superficiales encontramos tanto materiales protohistóricos como, en menor medida, modernos, los depósitos en hoyo de época ibérica se excavaron en los estratos geológicos, formados fundamentalmente por un conglomerado de matriz calcárea, con areniscas y margas. Los depósitos se ubican, por tanto, en hoyos de planta con tendencia oval o rectangular y con bases de tendencia cóncava y paredes curvas. Todavía de forma preliminar, podemos referirnos a un registro del que forman parte tanto restos faunísticos como humanos $\mathrm{y}$ en el que destacan formas cerámicas de pequeño tamaño como cuencos y páteras, metales como fíbulas de La Tène, anillos y las piezas aquí analizadas, así como otros elementos de cultura material como cuentas de collar de pasta vítrea. En algún caso no se ha logrado identificar la posible estructura negativa, por lo que planteamos que se trate de depósitos ubicados en relieves u oquedades llamativas, como las que origina las lajas de calcarenita características de estos afloramientos.

La excavación de estos depósitos se ha diseñado considerando la totalidad de su contenido como registro arqueológico. Por ello se ha flotado sistemáticamente todo el sedimento, además de plantearse la necesidad de un análisis post-excavación para determinar sus características sedimentológicas, tafonómicas, faunísticas y polínicas como forma de establecer hipótesis en cuanto a la valoración funcional de estos depósitos, intentando no caer en apriorismos o clasificaciones binarias de antemano.

En nuestra opinión, el registro empírico identificado en estas estructuras negativas revela unas prácticas centradas en la deposición secundaria de parte del registro generado en acciones sociales en las que sabemos que estuvo presente el fuego. Los depósitos forman así parte de una secuencia de acciones que vinculamos con prácticas de reproducción social e ideológica, incluyendo las funerarias y el recuerdo de los antepasados, por parte de la comunidad que habita o transita el valle de Jutia. El lugar elegido es especialmente relevante, en un pequeño afloramiento que destaca ligeramente en el fondo del valle, en un entorno presidido por surgencias (Fuente del Álamo, Fuente de Jutia) y cursos de agua (arroyo de Rivelte).

Aún en proceso de análisis, estas evidencias contextualizan y parecen corroborar la existencia de uno o varios monumentos en este entorno, caracterizado por la presencia de estruc- 
turas negativas y depósitos a los que nos hemos referido y donde encontramos los elementos de armamento que analizamos a continuación.

\section{A. FALCATA}

Fragmento de hoja de falcata de $3.4 \times 2.8 \times 0.6 \mathrm{~cm}$, de sección ligeramente trapezoidal. En una de las caras se observan decoraciones en forma de líneas rectas incisas, paralelas al lomo de la hoja. La pieza se encontró directamente en superficie, a escasos $2 \mathrm{~cm}$ de profundidad, en una zona cultivada unos $10 \mathrm{~m}$ al noreste del área monumental. El grado de deterioro es idéntico al del resto de piezas aparecidas en los depósitos excavados. La pieza originalmente hubo de formar parte de algún depósito y su ubicación actual se debería a los procesos postdeposicionales de la zona.

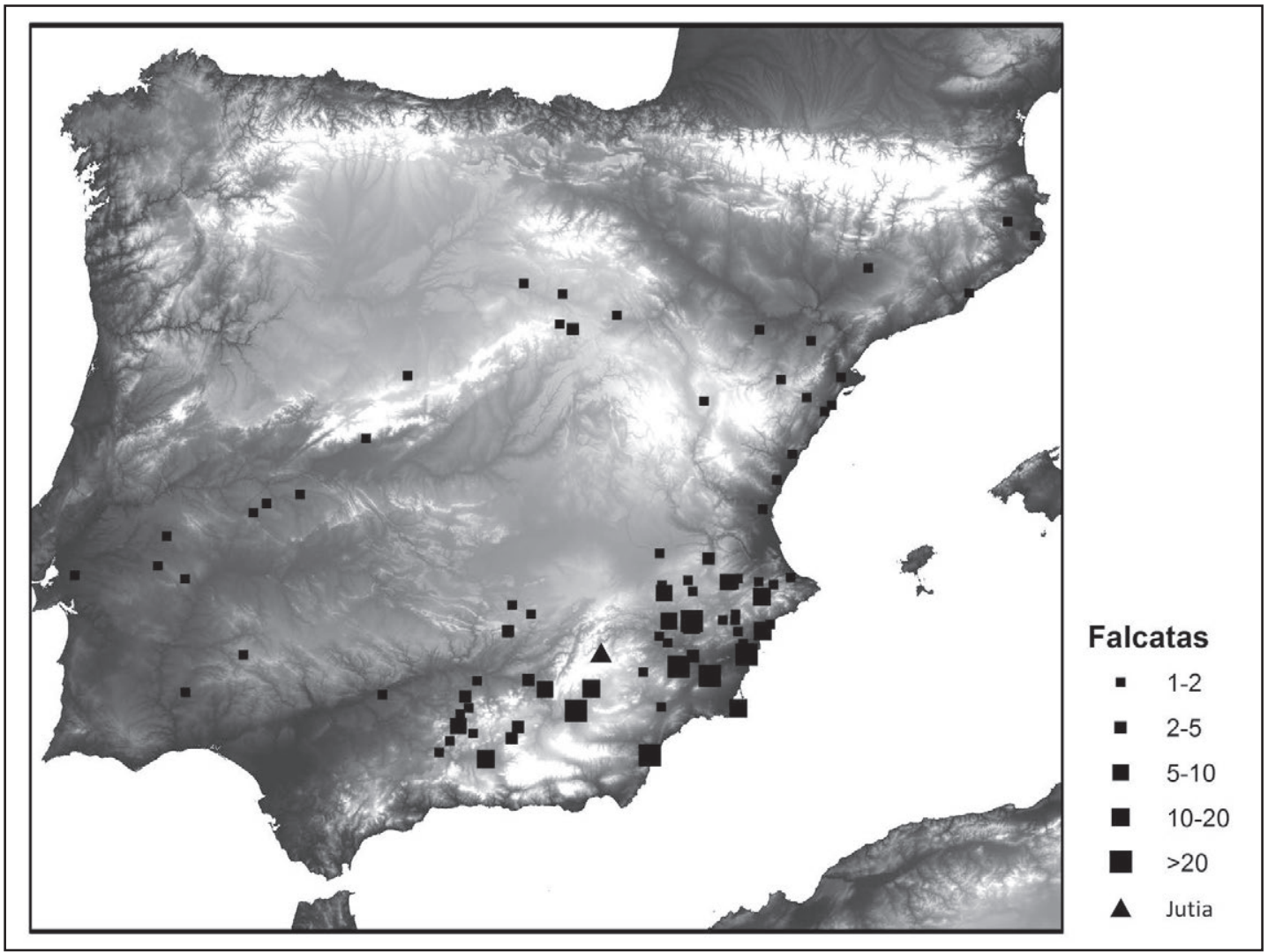

Figura 4. Dispersión de las falcatas documentadas en la Península Ibérica. Datos tomados de Quesada (1997: fig. 10).. El $\boldsymbol{\Delta}$ indica las evidencias documentadas en Jutia.

\section{B. Fragmento de ARMA o HERRAMIENTA DE CORTE}

Fragmento de herramienta de $2 \times 2.5 \mathrm{~cm}$, completamente encapsulado en productos de corrosión que no permiten distinguir su forma. Sin embargo, sí se puede apreciar su sección, 
que presenta un perfil triangular, con lomo ensanchado ligeramente en forma de " $\mathrm{T}$ " y caras rectas convergentes que terminan en un filo de sección levemente ojival. Al igual que con el fragmento de falcata, se trata de una pieza aparecida en prospección, a $6 \mathrm{~m}$ al norte de esta y por lo tanto a $16 \mathrm{~m}$ de la zona identificada con los depósitos de época ibérica. De nuevo la pieza se encontraba bastante superficial, a escasos $3 \mathrm{~cm}$ de profundidad, y posiblemente procedería de alguno de los depósitos destruidos por las labores agrícolas.

\section{C. MOHARRA DE LANZA}

Durante la excavación del depósito UE 57-58-68 se documentó un fragmento de moharra de lanza de apenas $3 \times 3 \times 3 \mathrm{~cm}$, en concreto una sección transversal de la misma casi perfecta. En la pieza resulta bien visible el nervio central y las dos mesas, aunque la escasa entidad del fragmento impide su identificación tipológica: parece tratarse de una sección del tipo 1 de F. Quesada (1997: 357), pero esta sección es aplicable a varias de las tipologías de lanzas elaboradas por el autor (Quesada, 1997: 394). Tampoco podemos, por lo tanto, proponer una cronología en función de la tipología, aunque cabría mencionar que la mayoría de los ejemplares conocidos con este tipo de sección se agrupan en el Sureste y la Alta Andalucía (Quesada, 1997: 395-396).

Esta pieza se halló, como se acaba de señalar, en el depósito UE 57-58,68. Se trata de un hoyo de medio metro de diámetro y unos $25 \mathrm{~cm}$ de profundidad aproximada, de planta oval y sección semiesférica, relleno de gredas disgregadas, cenizas y carbones y excavado parcialmente a su vez sobre otro depósito anterior, el UE 67-65-66, en el que, entre otros, se documentaron restos humanos. Por lo que respecta al contenido del depósito más reciente, el UE 57-58-68 además de la moharra de lanza se recogieron huesos, algunos carbones de pino (Pinus pinaster) y encina/coscoja (Quercus ilex/coccifera), y varios fragmentos cerámicos. Entre estas últimas, se cuentan cuatro galbos de minúsculas dimensiones, pasta oxidante y vestigios de haber sido quemados, y un quinto fragmento que comprendía prácticamente la mitad de una paterita (tipo III.8.2.2 de Mata y Bonet, 1992) de pasta reductora, borde reentrante y pie indicado, quemada previamente a su amortización, y cuyo diámetro en la boca no superaría los $7-8 \mathrm{~cm}$ a juzgar por la curvatura de sus paredes. Todos estos materiales se documentaron en el estrato superior del depósito, UE 58, compuesto de gredas disgregadas, en tanto que en el fondo del mismo, en el estrato UE 68, de contenido eminentemente cenizoso, tan solo aparecieron algunos restos óseos muy fragmentados y de difícil identificación. En este depósito, además, se recogió una semilla de rosácea, que ha sido analizada para determinar su datación radiocarbónica por el laboratorio de la universidad de Upsala, determinándose que la misma habría sido amortizada entre los ss. IV y III a. n. e. (con una probabilidad del 95,4\% entre el 399 y el 206 a. n. e., y una probabilidad del 68,2\% entre el 391 y 232 a. n. e.).

Por lo que respecta al depósito inferior (UE 67-65,66), por cierto, y aparte de los restos humanos mencionados, contenía tan solo algunos carbones y un fragmento de hierro de difícil identificación, todo ello comprendido en un relleno de areniscas muy disgregadas anaranjadas (UE 65) situadas sobre un estrato de tierras negras, restos humanos cremados y abundantes carbones que colmataba el fondo de la fosa (UE 66).

La fractura que dio como resultado el fragmento de lanza parece haberse producido con la pieza ya completamente corroída. Se trata de una fractura frágil, sin indicios de una deformación previa antes de desprenderse, que es lo que cabría esperar de una rotura predeposicional. Teniendo en cuenta las reducidas dimensiones del fragmento y las propiedades plásticas del hierro, debería apreciarse cierta deformación incluso en el caso extremo de un acero templado. 
Además, el aspecto de la cara de las fracturas, irregular y con variación radial de la corrosión, apoya la conclusión de que se trata de una rotura producida sobre la pieza corroída.

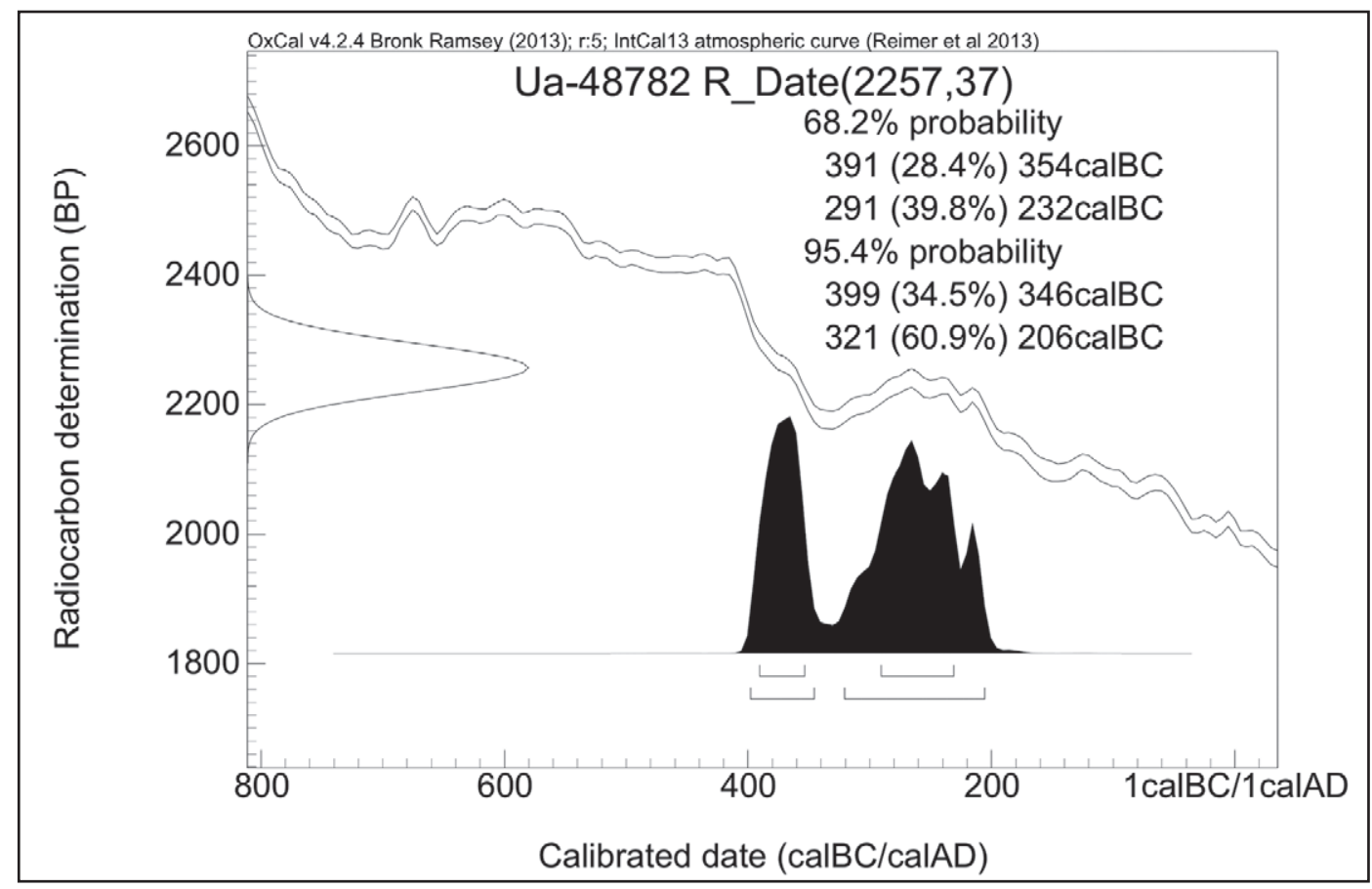

Figura 5. Datación radiocarbónica de una semilla de rosácea del depósito UE 57-58-68 de Jutia.

\section{D. SOLIFERREUM}

En el depósito UE 21 de Jutia se documentó la punta de un soliferreum. En realidad, se trata tan solo de la moharra, entendida en este caso como el extremo ofensivo del arma, relativamente corroída aunque entera, salvo por los últimos centímetros de la punta. El arma apareció dispuesta en sentido aproximado norte-sur, alineada con el pequeño lentejón cenizoso en cuyo interior se encontraba.

Por lo que respecta a la tipología del soliferreum, la forma convergente de las aletas en torno al nervio central y sus extremos traseros apuntados hacia afuera para actuar como anzuelos cuando el arma se clavara, permiten incluirlo en el tipo 3 de F. Quesada (1993: 165; 1997: 310), significativamente el más habitual en la Alta Andalucía pero no en el Sureste, donde resulta mucho más frecuentes los soliferrea del tipo 2, que a diferencia del nuestro muestran una punta estrictamente triangular (Quesada, 1993: 167; 1997: 311). La moharra de Jutia mediría en torno a los $6 \mathrm{~cm}$ (de los que conservamos 5), por lo que se encontraría muy próxima a la longitud media para estas armas (Quesada, 1993: 164; 1997: 311). En cuanto a la cronología de los soliferrea, el propio F. Quesada reconoce que la escasez de ejemplares bien conservados y documentados en contextos que puedan ser datados con precisión impide de momento establecer una seriación mínimamente precisa de estas armas, de modo que habremos de conformarnos con señalar que en el interior murciano, el sureste meseteño y la Alta Andalucía los soliferrea no parecen introducirse hasta el s. IV a. n. e., y se emplearán hasta finales de la siguiente centuria (Quesada, 1993: 170-172; 1997: 314-315). 


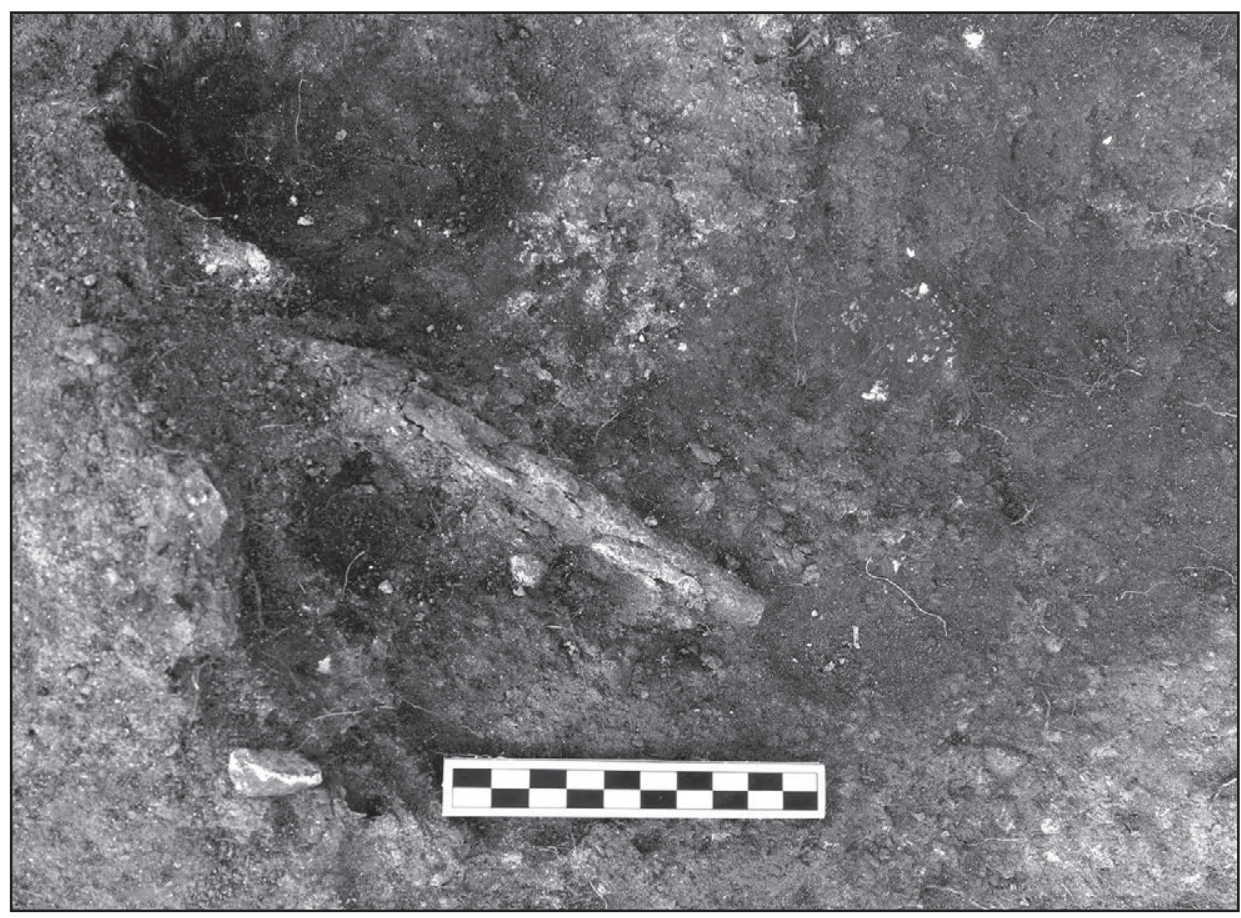

Figura 6. Hallazgo del soliferreum en el C-1, UE-21 de Jutia.

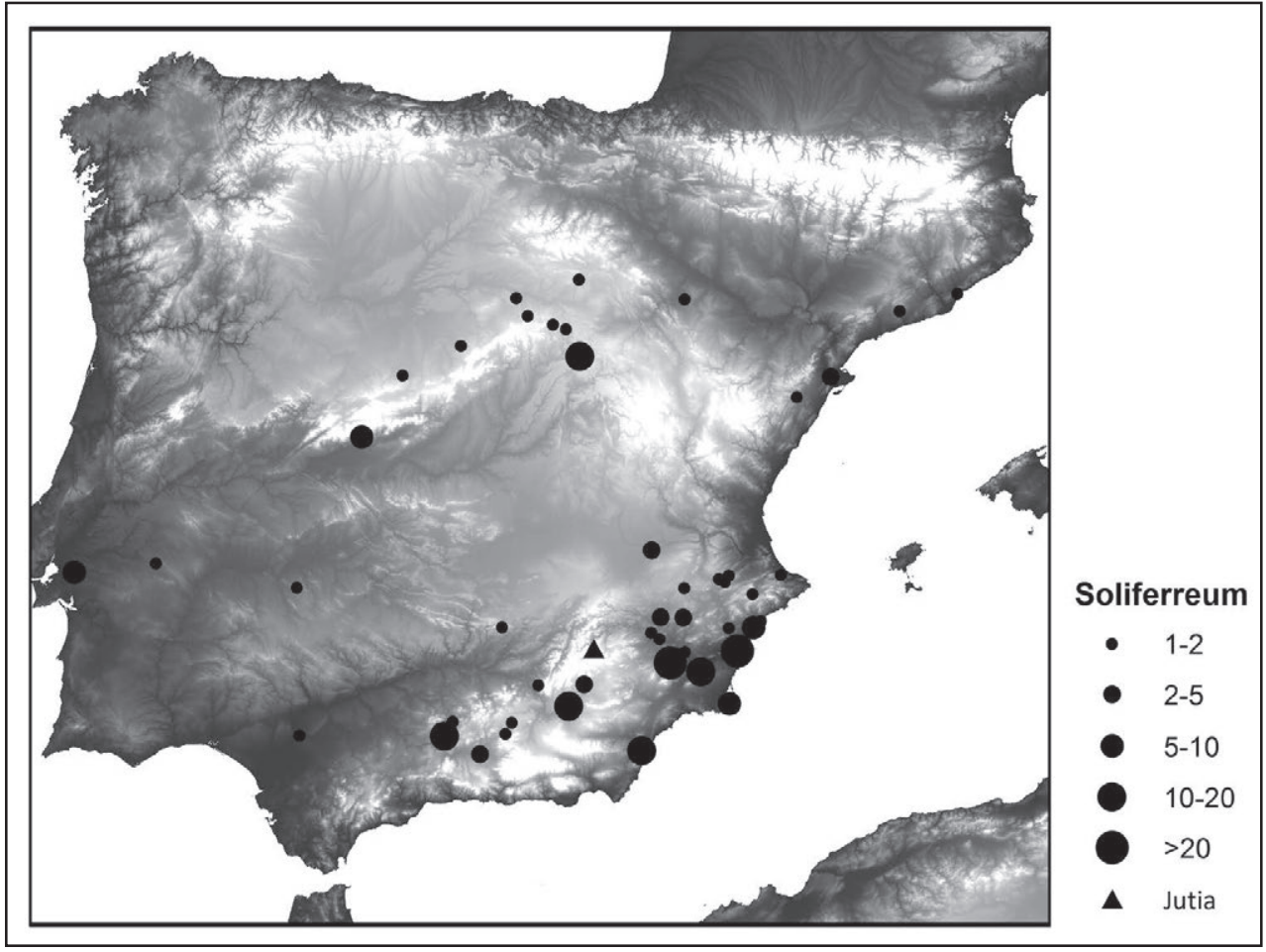

Figura 7. Dispersión de los soliferrea documentados en la Península Ibérica. Datos tomados de Quesada (1997: fig. 184). El $\boldsymbol{\Delta}$ indica las evidencias procedentes de Jutia. 
En cuanto al contexto de aparición de la pieza, la UE 21, hablamos de un pequeño depósito, un lentejón aproximadamente ovalado de tierra ennegrecida por su alto contenido en cenizas y carbones, y que seguramente se dispuso directamente sobre el suelo de uso o aprovechando un pequeño recoveco en este, pues a pesar de su cuidadosa excavación no pudo documentarse una unidad negativa. Sus dimensiones aproximadas en superficie son de unos 40x20cm, por apenas $10 \mathrm{~cm}$ de profundidad. En el interior de la mancha, y aparte del mencionado soliferreum, se documentaron abundantes carbones de coscoja (Quercus ilex/coccifera), así como varias decenas de pequeños fragmentos óseos de fauna, y dos minúsculos fragmentos cerámicos de apenas unos milímetros de longitud que fueron recuperados en la flotación del sedimento de la unidad estratigráfica y que posiblemente sean intrusivos, ambos oxidantes (aunque uno de cerámica tosca y otro de cerámica común) y ambos con vestigios de haber sido sometidos al fuego.

\section{RESULTADOS ANALÍTICOS}

\section{A. Fragmento de hoja de falcata:}

Se preparó una sección completa del fragmento de hoja (fig. 8a), pero su estudio al microscopio reveló que no quedaba ningún resto de núcleo metálico. Mediante la observación del perfil de la sección (fig. 8b), se pudo determinar que las acanaladuras presentes en la cara de la hoja se realizaron mediante burilado, probablemente en frío, como ya se ha documentado en numerosas ocasiones para este tipo de armas (por ejemplo en Prats Darder et alii, 1996, Lorrioet alii, 1998-1999 o Lang, 2014) y discutido extensamente (Quesada, 1988).

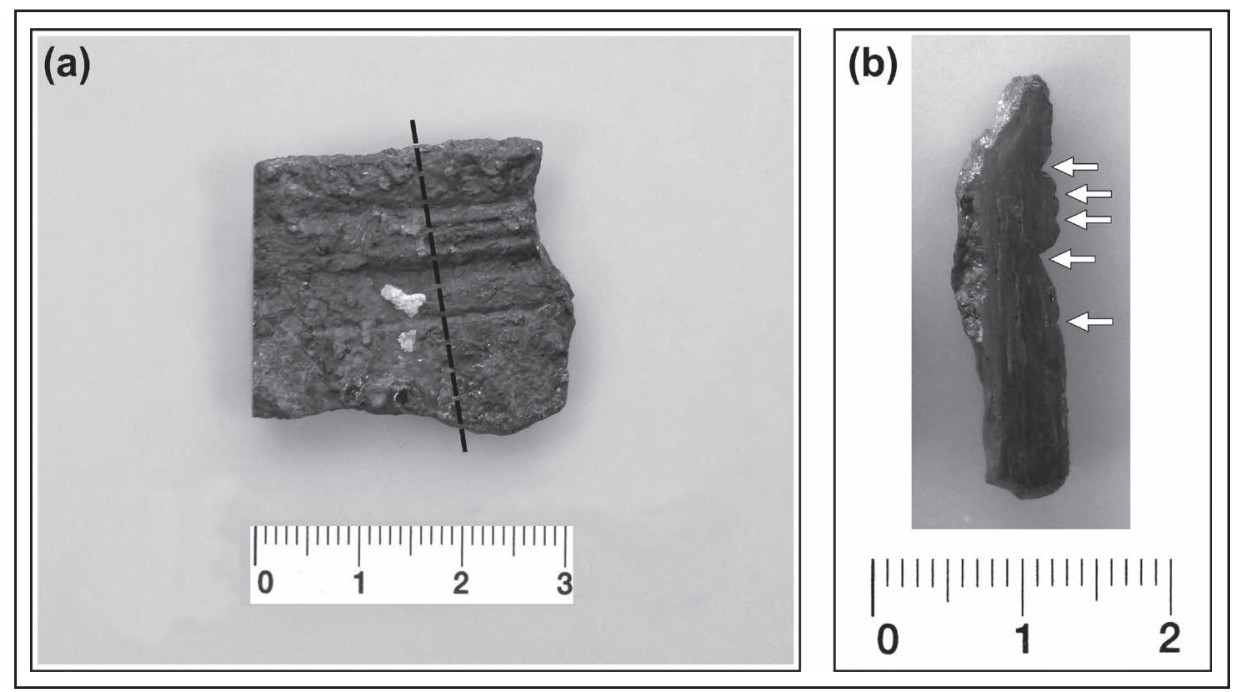

Figura 8. Fragmento de hoja de falcata. a) Vista de la cara con decoración incisa en forma de acanaladuras. La línea discontinua indica la posición de la sección estudiada. b) Vista de la sección. Las flechas indican la posición de las acanaladuras.

\section{B. FRAGMENTO DE HOJA DE ARMA O HERRAMIENTA:}

Se preparó una sección completa del fragmento de hoja (fig. 9a), pero su estudio al microscopio reveló que no quedaba ningún resto de núcleo metálico (fig. 9b). 


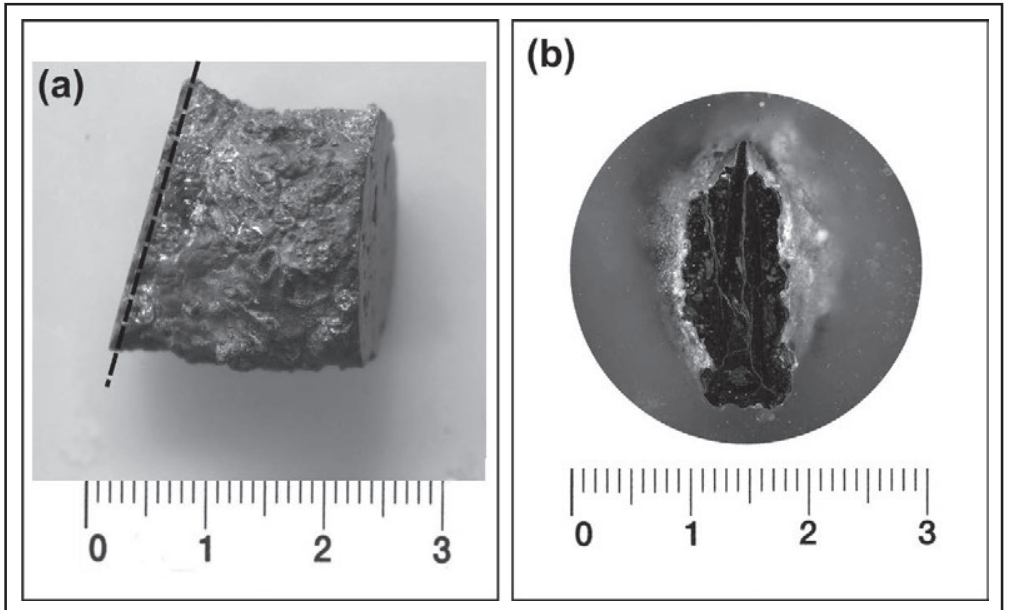

Figura 9. Fragmento de hoja de arma o herramienta a) Vista de la cara lateral de la pieza, con el conglomerado de productos de corrosión. La línea discontinua indica la posición de la sección que se estudió. b) Vista de la sección. Se distingue el perfil triangular, con el lomo de la hoja hacia abajo y el filo hacia arriba.
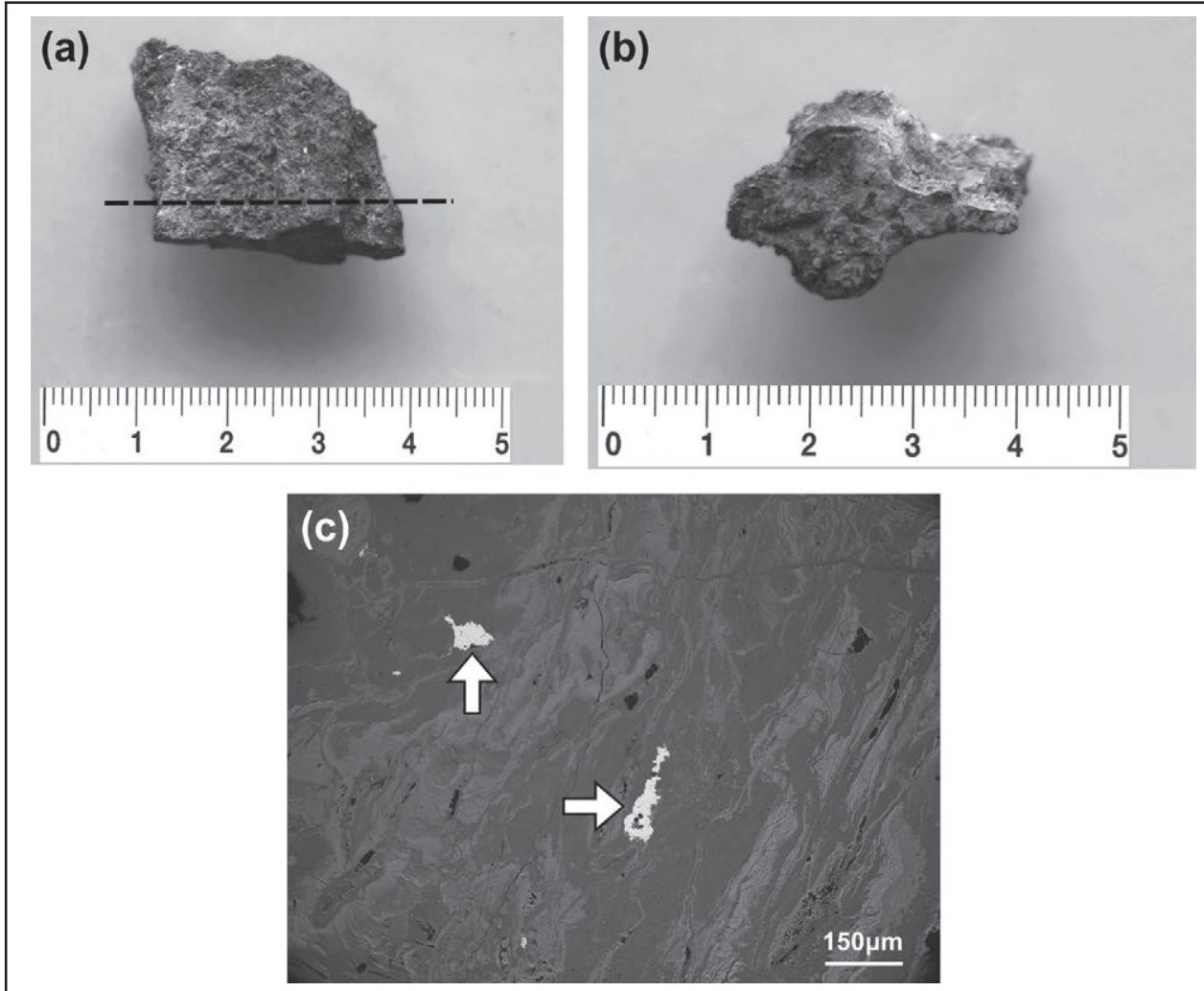

Figura 10. Moharra de lanza. a) Vista de una cara. La línea discontinua indica la posición de la sección que se estudió. b) Vista de la sección original. c) Metalografía $(\times 100)$. Las flechas indican los relictos microscópicos de hierro ferrítico. 


\section{C. MOHARRA DE LANZA:}

Se preparó y estudió una sección completa del fragmento de moharra de lanza (figs. 10a y $10 \mathrm{~b})$, pero estaba completamente corroída. Sólo se pudieron observar algunos relictos microscópicos (entre 50 y $150 \mu \mathrm{m}$, ver fig. 10c) de hierro ferrítico que no podían aportar información, así como confirmar la simetría radial de la corrosión cerca de superficie de fractura, indicando que se oxidó desde la superficie original de la moharra completa hacia adentro.

\section{D. PunTA DE SOLIFERREUM:}

Se prepararon dos muestras: una sección completa de la moharra y una sección completa del vástago (fig. 11a).

La sección de la moharra conserva núcleo metálico en su parte central, correspondiente al nervio (fig. 11b). Su microestructura presenta granos irregulares de ferrita y perlita distribuidos de forma heterogénea, de manera que en la parte que correspondería al núcleo del nervio se aprecia que el contenido en carbono es más alto $(0.7-0.8 \%$ de $\mathrm{C})$, y a medida que nos alejamos hacia la superficie va disminuyendo hasta alcanzar un 0.3-0.4\% C en los límites del núcleo metálico que se conserva, tal vez por un proceso de descarburización durante el conformado (figs. 12a y 12b). La perlita es fina, y se observan también algunas estructuras de tipo Widmanstätten que indican un enfriamiento relativamente rápido al final del proceso de fabricación, aunque no lo suficiente como para templar la pieza (figs. 12a y 12c).

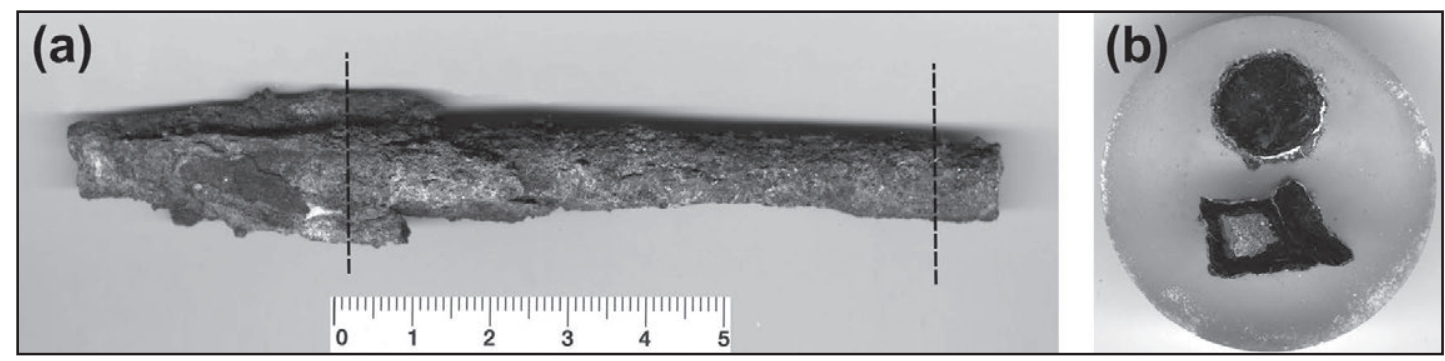

Figura 11. Punta de soliferreum a) Vista de una cara de la pieza. Las líneas discontinuas indican la posición de las secciones estudiadas. b) Imagen de las secciones estudiadas montadas en la probeta (Superior: vástago; Inferior: moharra).

El vástago no presenta núcleo metálico (fig. 11b), pero en algunas zonas los productos de corrosión conservan trazas de la estructura original ferrítico-perlítica, que permite aventurar para esa parte un contenido en carbono de alrededor del 0.3-0.4\% (figs. 13a y 13b).

Estos resultados indican que se trata de un acero (aleación de hierro y carbono) con un contenido en carbono bastante elevado, conformado mediante forja en caliente y terminado con un recocido parcial de tipo normalizado, que implica calentar la pieza por encima de los $700-800^{\circ} \mathrm{C}$ y dejarla enfriar al aire, en este caso de manera relativamente rápida, como indica la presencia de estructuras de Widmanstätten. El material resultante posee unas propiedades mecánicas muy adecuadas para la función que se le va a dar al objeto (Gener 2010: 205-212). Así, la moharra posee un núcleo de acero de alto contenido en carbono que le concede una dureza y rigidez fundamentales para que la punta no se doble al impactar contra el blanco, a 

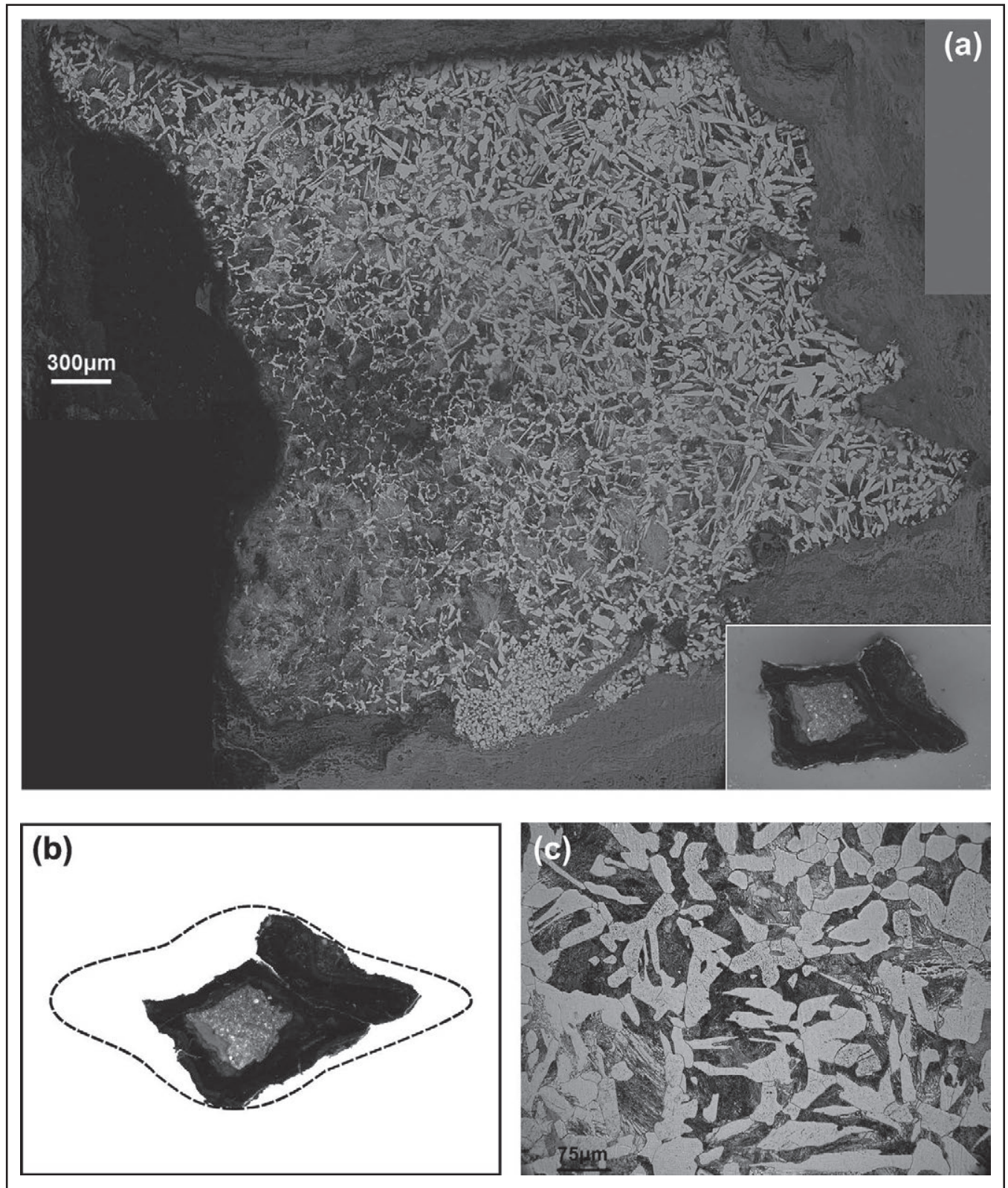

Figura 12. Punta de soliferreum a) Metalografía $(\times 50)$ de la sección de la moharra, donde puede apreciarse la estructura perlítico-ferrítica y la disminución de la concentración de C desde el núcleo (abajo-izda. de la imagen) a la superficie (arriba y dcha.). Imagen compuesta de varias metalografías. b) Esquema de la posición relativa del área estudiada metalográficamente en relación a la sección (aproximada) de la moharra. c) Metalografía $(\times 200)$ de la sección de la moharra, detalle. Ataque: picral al 4\% seguido de nital al 2\%.

pesar de tener detrás todo el peso del astil de metal integral característico de los soliferrea y que les proporciona su elevada capacidad de penetración. Por otro lado, ya se ha mencionado que la cantidad de carbono en la moharra disminuye progresivamente desde el núcleo a la superficie. Esto nos permite presumir que las aletas de la misma, a pesar de no conservar metal 

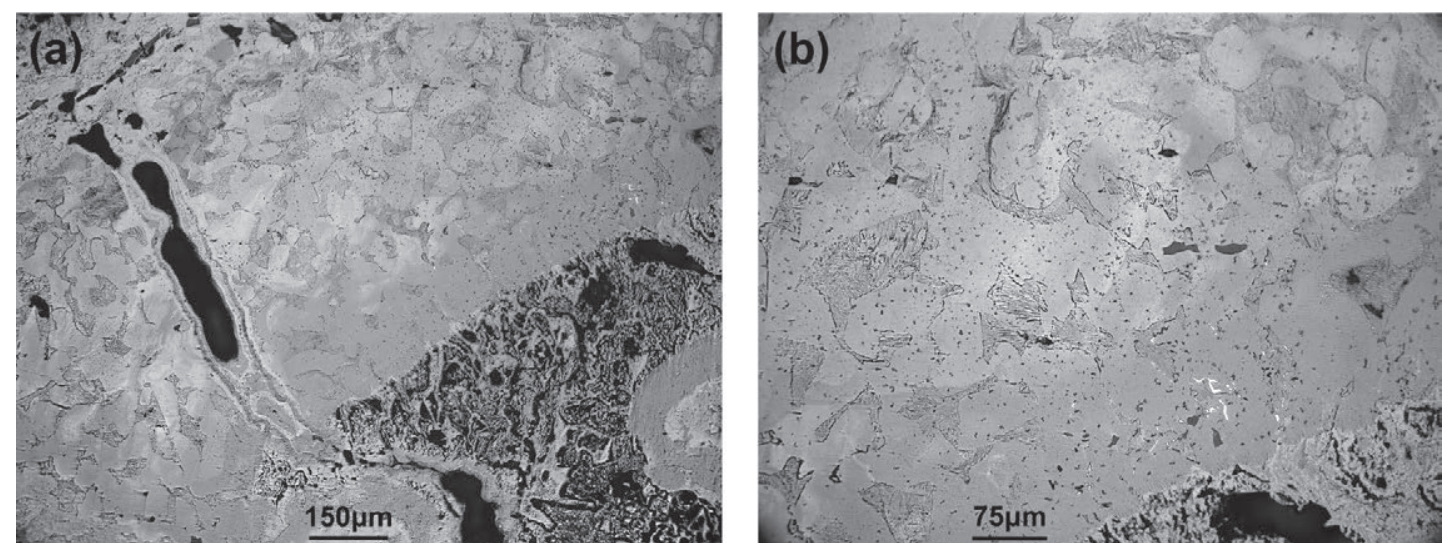

Figura 13. Punta de soliferreum a) Metalografía $(\times 100)$ de la sección del vástago, donde pueden apreciarse trazas de la estructura original en los productos de corrosión indicando la presencia de granos de perlita separados por áreas ferríticas. b) Metalografía $(\times 200)$ de la sección del vástago, detalle. Ataque: picral al $4 \%$ seguido de nital al $2 \%$

ni estructura remanente, habrían estado hechas de un acero que poseería suficiente dureza, aún siendo menos duro que el del núcleo, como para ofrecer un filo perfectamente operativo para este tipo de arma. La disminución de carbono es gradual, lo cual indica que es producto de un proceso de descarburación, probablemente debido a que la pieza haya sido sometida a condiciones oxidantes en la forja durante su conformado. Esto habría causado la pérdida progresiva de parte del carbono contenido en el metal, es de suponer que de manera involuntaria. Otra posible causa para la descarburación, y para el estado de recocido que presenta la pieza, es que ésta formara parte de un ajuar funerario y haya sido sometida a un proceso de incineración como parte del ritual fúnebre, una costumbre habitual entre los íberos (Quesada, 1997: 642-643; Reig, 2000). El calor de la incineración podría además haber eliminado la evidencia de tratamientos térmicos de templado, que le hubieran proporcionado fácilmente a este tipo de acero un endurecimiento adicional.

El vástago, a su vez, estaba constituido por un acero con menos carbono, aunque suficiente para proporcionarle también la rigidez que necesita para mantener la forma bajo las tensiones de su uso, así como la tenacidad precisa para absorber los impactos sin romperse.

El soliferreum era un arma diseñada para ser arrojada manualmente contra un enemigo y resultar particularmente eficaz a la hora de penetrar sus defensas corporales. La encontramos mencionada en diversas fuentes clásicas, en manos de los pueblos peninsulares. Así, de entre las referencias literarias grecorromanas que ya F. Quesada citaba en su tesis doctoral (Quesada, 1997) y mencionadas después cuando se han abordado este tipo de cuestiones, nos encontramos con que ya Diodoro $(\mathrm{V}, 34)$ señala que los lusitanos usan unos dardos enteramente

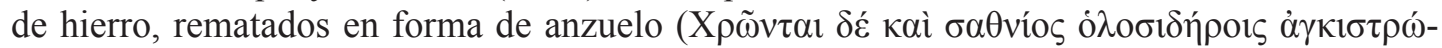
$\delta \varepsilon \sigma \mathrm{l})$; Livio (XXXIV, 14, 10) menciona que los ilergetes que luchan contra Catón emplean primero sus soliferrea arrojadizos, y luego desenvainan las espadas para luchar cuerpo a cuerpo (Ut emissis soliferreis falariscique gladios strinxerun); Plutarco (Aem. Paul. 19, 9) cuenta que en la Batalla de Pidna Perseo es herido por un olosideros arrojado por las tropas de Emilio Paulo (antiguo procónsul de la Hispania Ulterior) y Apiano (Bell. Civ. V, 8) relata que Menécrates, general de Sexto Pompeyo, es herido en el 38 a. n. e. por un olosideros ibérico de punta barbada. Los autores de la época también destacan la gran capacidad perforante de las armas arrojadizas ibéricas (la falárica empleada por los defensores saguntinos, por poner un ejemplo, traspasaba tanto las armaduras como los cuerpos [Liv. 21, 8, 11]). Este era el caso 
del soliferreum, que se fabricaba enteramente en hierro y estaba equipado con una moharra pequeña pero sólida y afilada, algo más grande que el vástago que la sujetaba, con el fin de que si la cabeza se abría paso el astil la siguiera en su recorrido sin oponer resistencia. El peso del conjunto le proporcionaba una inercia considerable al ser arrojada. Si en el momento del impacto el astil mantenía una rigidez suficiente para transmitir toda la inercia a la punta, y esta era lo bastante dura para penetrar en el blindaje, la moharra disponía de mucha energía para abrirse paso, resultando en una gran capacidad de perforación. Y podemos decir que los resultados obtenidos en el análisis indican que este ejemplar presenta unas propiedades mecánicas suficientemente adecuadas para este propósito, incluso considerando que los resultados observados son intencionales, y no el producto accidental de una incineración.

En este sentido, nuestros resultados contrastan con los obtenidos para el único soliferreum de la Península Ibérica analizado metalográficamente y publicado hasta la fecha (Gener y Montero, en prensa), un ejemplar proveniente del yacimiento de Aguilar de Anguita, depositado en el Museo Arqueológico Nacional de Madrid y estudiado en Madroñero de la Cal (19831984). El análisis se llevó a cabo sobre un fragmento del vástago, y el autor concluye que el soliferreum estaba hecho de acero con un contenido en carbono de aproximadamente $0.15 \%$, forjado extensivamente y recocido al final. Pese a discrepar con otras conclusiones expresadas en el artículo y que hacen referencia a un posible tratamiento superficial, las metalografías que se aportan confirman estas afirmaciones, y de ellas también podemos derivar que la concentración de $\mathrm{C}$ es algo menor cerca de la superficie (aproximadamente $0.1 \%$ ). Con este resultado se pude afirmar que el ejemplar de Aguilar de Anguita sería menos duro y menos rígido que el de Jutia, y se doblaría con más facilidad. Ambos ejemplares tienen en común la descarburización (muy ligera en el caso del ejemplar de Aguilar de Anguita) y el recocido final, pero esto, de nuevo, puede ser producto de la incineración.

\section{CONCLUSIONES}

El primer objetivo de este trabajo ha sido valorar y analizar críticamente los datos procedentes de una serie de análisis metalográficos de diferentes objetos de época ibérica. En nuestro caso todos los objetos provienen de un territorio del sureste peninsular escasamente conocido como es la cuenca alta del río Segura en el reborde oriental de los sistemas béticos. La prioridad tradicional de los estudios respecto a las zonas costeras y los lugares centrales $\mathrm{u}$ oppida ha conllevado una menor dedicación y, en todo caso, un conocimiento descompensado, puntual y escaso respecto a las condiciones de vida y las formas productivas de las comunidades rurales en paisajes de montaña como Jutia.

La atención que hemos prestado a los elementos de armamento se justifica en cuanto son una buena vía de aproximación hacia los discursos ideológicos de los visitantes del espacio ritual. Al fin y al cabo, para la época ibérica tardía los autores grecorromanos atestiguarán que para los iberos la posesión de armas era un símbolo metonímico de su propia libertad (App., Ib. 31; Dio. Cas. fr. 75; Flor. 1, 34) y que las consideraban el atributo identitario de todo un grupo social (Polib. 10, 18, 6) (Quesada, 1992: 38-42). Pero ya desde los momentos formativos de la cultura ibérica podemos observar que las elites se hicieron representar a sí mismas sistemáticamente, pese a ciertos matices según las épocas, como guerreros armados (García Cardiel, 2014). Y en las propias necrópolis, por cierto, nos encontramos con que un nutrido grupo de individuos se hará enterrar acompañado de armas, y que lo hará hasta momentos avanzados de la disolución del mundo ibérico en el romano (Quesada, 1989: 114-116). Todo lo cual sugiere, en nuestra opinión, que la posesión y ostentación de armas constituía un elemento 
de distinción social de gran importancia para un sector de la sociedad ibérica, un signo de gran importancia a la hora de construir y negociar su identidad social en el seno de la comunidad en tanto que co-responsable de la defensa de la misma.

Conviene también tener presente cómo hay momentos del proceso histórico de las sociedades ibéricas en que el acceso a las armas se generaliza de forma notable. Se ha hablado, a juzgar por el registro de las grandes necrópolis del sureste y de la meseta, de un acceso generalizado a las armas por parte de los habitantes libres propietarios (Quesada, 2010b, 37). Es cierto que las necrópolis ibéricas parecen registrar el comportamiento ante la muerte de un determinado sector de la población, pero esta abundancia de armas en ciertas épocas nos hace ser prudentes en cuanto a su significado polisémico y cambiante. En este sentido, nos interesa subrayar dos cuestiones. Por una parte, que aunque la asociación de las armas con determinadas construcciones ideológicas fue sin duda importante, es imprescindible contextualizar la presencia de armas con el resto de elementos que formalizan en cada momento esa ideología. Por otra, que los diversos tipos de armas son susceptibles de haber sido utilizados en diferentes discursos, a lo largo del tiempo y de los territorios ibéricos, y que contienen por tanto una potencial polisemia cuya exploración es de gran interés para no uniformizar los discursos que elaboramos sobre la presencia de armas en los lugares rituales y funerarios ibéricos. Por ejemplo, es interesante la posibilidad de explorar las diferencias existentes entre la disposición de las armas en una tumba tumular, generalmente completas, cuidadosamente colocadas y formando parte de un ajuar con ítems más o menos habituales o de prestigio, y el depósito del arma en sí, o miniaturizada, de los santuarios (Gabaldón, 2004: 363), más similar a lo que observamos en Jutia.

Además del potencial que conllevan estas diferencias contextuales, es interesante explorar toda actitud o acción social sobre las armas, teniendo en cuenta que, a pesar de su relativa abundancia en los asentamientos (Quesada, 2010b), con algunos hallazgos recientes destacables (Bonet et alii, 2011; Vives-Ferrándiz et alii, 2015), nos movemos habitualmente en contextos fuertemente connotados desde el punto de vista simbólico.

Este tratamiento de las armas en los rituales, funerarios o no, ha sido ampliamente tratado y es bien conocido. Queremos no obstante añadir el debate surgido a partir de los estudios metalúrgicos aplicados a la lanza, ya expuestos, en la medida en que nos parece un ejemplo de cómo las analíticas aportan argumentos que, en el marco de un trabajo interdisciplinar conjunto, pueden adquirir trascendencia para el debate arqueológico e histórico.

En el fragmento de la moharra de lanza que hemos estudiado las distintas observaciones y analíticas indican que este solo pudo haber sido seccionado cuando el arma ya estaba oxidada, esto es, varias décadas (puede que incluso generaciones) después de que el arma hubiera dejado de cumplir su función como tal. Es importante precisar que esta observación en cuanto a la fragmentación del arma adquiere además sentido en cuanto es coherente con el tratamiento observado en otros materiales del contexto de Jutia. Las analíticas realizadas y el contexto arqueológico aportan, por tanto, argumentos convergentes y esto nos permite abrir una pequeña reflexión sobre las implicaciones de este posible tratamiento o acción social que refleja la cultura material de Jutia.

Hay una serie de posibles líneas explicativas para este estado del registro de Jutia. Por una parte, podríamos encontrarnos ante la evidencia de la amortización de un objeto "con historia", de una lanza que podría haber pertenecido a la familia del difunto durante un largo lapso de tiempo, o bien de un arma que hubiera sido amortizada previamente en el depósito ritual anterior, el UE 67-65-66, y que al haber sido este parcialmente destruido (voluntaria o involuntariamente) al excavarse el nuevo depósito UE 57-58-68, los responsables de esta última acción hubieran decidido seccionarla y volver a introducir uno de sus fragmentos en 
la nueva tumba. Como ya indicamos, el 100\% del sedimento de todos los depósitos y de sus estratos superiores ha sido recogido y flotado sistemáticamente, y no hemos encontrado ningún otro fragmento que pueda adscribirse a una lanza. Por otra, el hallazgo nos podría hacer pensar en un fragmento poco conocido de Aristóteles (y escrito, por tanto, hacia las mismas fechas en las que estos rituales se estaban produciendo), según el cual los iberos tenían la costumbre de señalizar las tumbas de sus guerreros con jabalinas (siguiendo la tra-

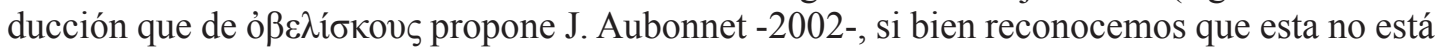
exenta de problemas) hincadas en torno a ellas (Arist. Pol. 7, 1324b), armas que expuestas de este modo no tardarían en oxidarse, y cuyo destino último no obstante ignoramos. Hay otras explicaciones plausibles, como que el arma hubiese quedado durante un tiempo prolongado en un quemadero utilizado recurrentemente y se hubiese recogido después, durante el ritual asociado a la muerte de otro miembro de la comunidad, como se ha argumentado en otros contextos (Jones, 2007). O que hubiese pasado un tiempo en una casa, quizás custodiada por la familia a modo de objeto familiar o reliquia, tal y como se ha estudiado en otros ámbitos de la Edad del Hierro peninsular (Sanz Mínguez, 2008), aunque carecería aquí, en principio, de las condiciones ambientales para deteriorarse en un plazo razonable.

En cualquier caso, la circunstancia de que este arma tantas veces reutilizada, con una "vida" tan ajetreada, fuera seccionada antes de su amortización última, de hecho, tampoco debe extrañarnos. En el ritual funerario ibérico, y en concreto en el que se pone de manifiesto en el espacio ritual de Jutia, la fragmentación (fenómeno estudiado para otras sociedades prehistóricas: cf. Chapman, 2000; Chapman y Gaydarska, 2007) parece tener un papel protagonista. Esto refuerza la posibilidad de que la fragmentación de la moharra de lanza fuera intencional, ya que el tratamiento dado a la lanza encaja perfectamente con el tratamiento dado a gran parte del registro arqueológico de Jutia. También los recipientes cerámicos no quemados parecen haber sido seccionados previamente a la inclusión de algunas de sus partes en los depósitos, e incluso los restos humanos, por su escasez relativa, podrían no corresponder a cadáveres enteros sino solo a una parte de los mismos, aunque esto último requiere del estudio paleoantropológico actualmente en curso que confirme, o no, esta posibilidad, teniendo en cuenta las dificultades que esto conlleva por la naturaleza de este registro y por el proceso de cremación experimentado.

Por su parte, hemos determinado que el soliferreum estudiado está fabricado en acero. Su contenido en carbono varía entre un $0.7-0.8 \%$ de $\mathrm{C}$ en el núcleo de la moharra hasta un 0.3 $0.4 \%$ cerca de la superficie de la misma y en el vástago. Fue sometido a un proceso de recocido/normalizado como último paso en su fabricación, aunque no es descartable que se trate de los efectos de una incineración. En cualquier caso, las propiedades mecánicas asociadas a las microestructuras estudiadas resultan muy adecuadas para la función asignada a este tipo de arma. Debido a las condiciones de conservación del conjunto, este ha sido el único objeto de armamento de hierro del que se han podido obtener resultados metalúrgicos significativos, con lo que el grado de representatividad de las conclusiones es limitado. A la espera de poder estudiar los materiales que se obtengan en futuras campañas de excavación, sólo podemos comparar los resultados de este análisis con los de otra pieza peninsular parecida, de propiedades mecánicas más pobres. Lamentablemente, la falta de más análisis no permite sacar conclusiones más amplias sobre el control de la tecnología del hierro que tenían los íberos. Sin embargo, estos resultados recalcan una vez más la necesidad de estudios arqueometalúrgicos amplios, sistemáticos y ambiciosos que nos permitan, en este caso, determinar adecuadamente qué parte de la chaîne operatoire observada en los diversos elementos del armamento prerromano peninsular en hierro es intencional, con fines funcionales, y qué parte accidental, debido a aplicaciones desiguales del conocimiento tecnológico o a procesos predeposicionales que nada tienen que ver con la fabricación y el propósito del objeto, como puede ser la incinera- 
ción. Sabemos que los íberos poseían la capacidad de producir armamento de construcción compleja, como falcatas fabricadas con hierro y acero de diferentes contenidos en carbono (ver por ejemplo Nieto y Escalera, 1970, Lorrio et alii, 1998-1999 o Lang, 2014), pero los pocos estudios metalúrgicos publicados hasta la fecha no permiten todavía hacernos una idea clara del control que tenían sobre este tipo de metalurgia (Gener y Montero, en prensa), una situación que intentamos remediar con estudios como los publicados aquí.

Es importante hacer énfasis en que este tipo de estudios sistemáticos, ordenados y minuciosos, que garanticen unos ciertos niveles de fiabilidad, tienen una proyección mucho más allá del yacimiento o territorio donde se aplican. Los resultados obtenidos deben facilitar la creación de un marco referencial que permita realizar análisis comparativos de manera fiable, colocando los estudios en un contexto territorial más amplio y multiplicando así su utilidad. Un ejemplo paradigmático de esta utilidad lo constituye el Proyecto de Arqueometalurgia de la Península Ibérica, que desde sus inicios en los años 80 (Rovira et alii, 1997; Delibes de Castro y Montero Ruiz, 1999; Rovira Llorens y Gómez Ramos, 2003) ha acumulado hasta el día de hoy cerca de 30.000 análisis composicionales y metalográficos de metales arqueológicos e históricos, sobre todo de base cobre, pero también de oro, plata, plomo y, en menor medida, hierro, de tal manera que actualmente constituye una herramienta imprescindible para llevar a cabo estudios comparativos sobre tecnología metalúrgica peninsular en cronologías que abarcan desde el Calcolítico a la Edad Media, y que no deja de incorporar datos de manera continua. No es sólo el volumen de datos acumulado lo que permite a día de hoy poder realizar este tipo de estudios comparativos y estadísticos, sino el hecho de que los datos han sido obtenidos de manera sistemática y metodológicamente coherente, de manera que ahora pueden tratarse en bloques, y relacionarse entre ellos de manera significativa. Es la planificación y metodología detrás de este tipo de iniciativas lo que resulta imprescindible para que los datos obtenidos puedan alcanzar su pleno potencial, obteniendo pleno beneficio de los costes y el esfuerzo que se han invertido en su obtención.

Estos programas de investigación proporcionan además un marco para la integración de las perspectivas arqueológicas y analíticas que hemos defendido e intentado plasmar en este trabajo. Esta convergencia de aproximaciones constituye en nuestra opinión el espacio adecuado no sólo para multiplicar los datos y por tanto las posibles respuestas a las problemáticas históricas planteadas sino también, y sobre todo, para poder cambiar las preguntas que dirigen nuestra investigación sobre las condiciones de vida en el pasado.

\section{BIBLIOGRAFÍA}

Aubonnet, J. (trad.) (2002): Aristote. Tome III ler partie: Livre VII. Paris, Les Belles Lettres.

Bonet Rosado, H. y Vives-Ferrándiz Sánchez, J. (eds.) (2011): La Bastida de les Alcusses, 1928-2010. Valencia,Museu de Prehistòria de València.

Chapa Brunet, T. (2007-2008): "Esculturas ibéricas de El Álamo-Jutia (Yeste-Nerpio, Albacete)". Boletín de la Asociación Española de Amigos de la Arqueología 45: 79-92.

Chapa Brunet, T. y Mayoral Herrera, V. (2007): Arqueología del trabajo: el ciclo de la vida en un poblado ibérico. Madrid, Akal.

Chapman, J. (2000): Fragmentation in archaeology. People, places and broken objects in the prehistory of South Eastern Europe. Londres-Nueva York, Routledge.

Chapman, J. y Gaydarska, B. (2007): Parts and wholes. Fragmentation in Prehistoric context. Oxford, Oxbow.

Delibes de Castro, G. y Montero Ruiz, I. (1999): Las primeras etapas metalúrgicas en la Península Ibérica. Vol. 2, Estudios regionales. Madrid, Instituto Universitario Ortega y Gasset. 
Farnié, C. y Quesada, F. (2005): Espadas de hierro, grebas de bronce. Símbolos de poder e instrumentos de guerra a comienzos de la Edad del Hierro en la Península Ibérica. Murcia, Museo de Arte Ibérico de El Cigarralejo.

Fernández Flores, A. (1999): "El uso de detectores de metales en intervenciones arqueológicas urbanas: métodos de aplicación y resultados" XXV Congreso Nacional de Arqueología: 24 al 27 de Febrero, 1999, Valencia. Diputación de Valencia, Valencia: 258-261.

Fernández Flores, A. (2003): "Introducción al detector de metales como herramienta básica para la recuperación de material numismático en intervenciones arqueológicas"XI Congreso Nacional de Numismática: del 16 al 19 de Octubre, 2002, Zaragoza. Madrid, Real Casa de la Moneda: 369-376.

Gabaldón Martínez, M. del M. (2004): Ritos de armas en la Edad del Hierro. Armamento y lugares de culto en el antiguo Mediterráneo y el mundo celta. Anejos de Gladius. CSIC, Madrid.

García Cardiel, J. (2014): "El combate contra el Mal: imaginarios locales de poder a través de la conquista romana en el Levante ibérico".Complutum,25 (1): 159-175.http://dx.doi.org/10.5209/ rev_cmpl.2014.v25.n1.45361

García Cardiel, J. (2015): La imagen del poder en el mundo ibérico del Sureste (siglos VII-I a. C.) y su articulación en el paisaje. Tesis doctoral, Madrid, Universidad Complutense de Madrid.

García Jiménez, G. (2011): El armamento de influencia La Tène en la Península Ibérica (siglos V-I a. C.). Montagnac, Mergoil.

Gener Moret, M. (2010): “Tecnología de la metalurgia del hierro". Montero Ruiz, I. (coord.), Manual de Arqueometalurgia, Alcalá de Henares-Madrid, Museo Arqueológico Regional de la Comunidad de Madrid y Sección de Arqueología del CDL de Madrid: 189-232.

Gener Moret, M. (en prensa): "Carp's tongue swords and their use. Functional, technological and morphological aspects". Horn, C. (ed.), Warfare in Bronze Age Society. The Impact of Combat and Warfare on Societies in Bronze Age Europe and Beyond. Cambridge University Press.

Gener Moret, M. y Montero, I. (en prensa): "Los estudios arqueometalúrgicos de armamento de la Península Ibérica del periodo prerromano (s. VI-I ANE). Situación. Problemas. Soluciones”. Graells, R. y Marzoli, D. (eds.), Bewaffnung und Krieges auf der Iberischen Halbinsel in vorrömischer Zeit (6. -1. Jh. v. Chr.): Probleme, Ziele und Strategien / Armamento y guerra en la península ibérica prerromana (s. VI-I a. C.): problemas, objetivos y estrategias, Verlag des Römisch-Germanischen Zentralmuseums (RGZM).

González Reyero, S. (2013): Documentación y estudio del poblamiento ibérico en la cuenca alta del río Segura (Albacete). Interacción entre paisajes simbólicos y espacios productivos. Toledo, Consejería de Cultura, Junta de Castilla-la Mancha.

González Reyero, S.; Chapa Brunet, T; Sánchez-Palencia Ramos, F. J. y García Cardiel, J. (en prensa): "Las comunidades iberas en paisajes de montaña. La cuenca alta del río Segura". I Reunión Científica de Arqueología de Albacete, Museo de Albacete, 22 y 23 de enero de 2015.

González Reyero, S.; Renzi, M. y Sánchez-Palencia, J. (2015): “Metalurgia en la cuenca alta del río Segura durante la Edad del Hierro. Caracterización y estudio preliminar”. Minería y metalurgia en el mediterráneo y su periferia oceánica, III Encuentros Internacionales del Mediterráneo, Mazarrón, Phicaria: 129-146.

Grau Mira, I. y Reig Seguí, C. (2002-2003): "Sobre el uso de metales en la Contestania Ibérica las evidencias de La Serreta". Recerques del Museu d'Alcoi, 11-12:101-150.

Kristiansen, K. (2002): "The tale of the sword - swords and swordfighters in Bronze Age Europe". Oxford Journal of Archaeology, 21 (4): 319-332. http://dx.doi.org/10.1111/1468-0092.00166

Jones, A. (2007): Memory and Material Culture. Cambridge, Cambridge University Press (Topics in Contemporary Archaeology).

Lang, J. (2014): "Iberian falcata in the British Museum". Pernicka, E. y Schwab, R. (eds.), Under the volcano: proceedings of the International Symposium on the Metallurgy of the European Iron Age (SMEIA) held in Mannheim, Germany, 20-22 April 2010. Rahden/Westf, Verlag Marie Leidorf $\mathrm{GmbH}$, Forschungen zur Archäometrie und Altertumswissenschaft: 49-58.

López Precioso, J.; Jordán Montés, J. y Soria Combadiera, L. (1992): “Asentamiento ibéricos en el Campo de Hellín. Su relación con el trazado viario y la red comercial”. Verdolay, 4:51-62.

Lorrio, A. J.; Rovira, S. y Gago Blanco, F. (1998-1999): "Una falcata damasquinada procedente de la Plana de Utiel (Valencia): estudio tipológico, tecnológico y restauración”. Lucentum, 17-18: 149161. http://dx.doi.org/10.14198/lvcentvm1998-1999.17-18.07 
Madroñero de la Cal, A. (1983-1984): “Aplicación de las técnicas arqueometalúrgicas en la identificación e interpretación de los restos de soliferreums". Kalathos, 3-4: 139-148.

Mata, C. y Bonet, H. (1992): "La cerámica ibérica: ensayo de tipología". Estudios de arqueología ibérica y romana. Homenaje a Enrique Pla Ballester. Valencia, Diputación Provincial: 117-173.

Mata Parreño, C.; Moreno Martín, A. y Ferrer Eres, M. A. (2009): "Iron, fuel and slags: reconstructing in their onworking process in Iberian Iron Age (Valencian Region)". Pyrenae: revista de prehistòria $i$ antiguitat de la Mediterrània Occidental, 40 (2): 105-127.

Mödlinger, M. (2010): “Una potente arma per uccidere: la produzione di spade nell'Europa centrale dell'età del bronzo". Notizie Archeologiche Bergomensi, 18: 83-98.

Mödlinger, M. (2012): "European Bronze Age Cuirasses: aspects of chronology, typology, manufacture and usage". Jahrbuch des Römisch-Germanischen Zentralmuseums Mainz, 59: 1-49.

Mödlinger, M. (2013): "Bronze Age bell helmets: new aspects on typology, chronology and manufacture". Praehistorische Zeitschrift, 88 (1-2). http://dx.doi.org/10.1515/pz-2013-0005

Molloy, B. (2008): "Martial arts and materiality: a combat archaeology perspective on Aegean swords of the fifteenth and fourteenth centuries BC". World Archaeology, 40 (1): 116-134. http://dx.doi. org/10.1080/00438240701843611

Molloy, B. (2009): "For Gods or Men? A Reappraisal of the Function of European Bronze Age Shields". Antiquity, 83: 1052-1064.http://dx.doi.org/10.1017/s0003598x00099348

Molloy, B. (2011): "Use-wear analysis and use-patterns of Bronze Age swords". M. Uckelmann; M. Mödlinger (eds.), Warfare in Bronze Age Europe: manufacture and use of weaponry. Oxford, Archaeopress: $67-84$.

Nieto, G. y Escalera, A. (1970): "Estudio y tratamiento de una falcata de Almedinilla". Informes y Trabajos del Instituto de Conservación y Restauración de obras de Arte, Arqueología y Etnología, 10: 5-30.

Noguera, J., Ble, E., Valdés, P. (2015): “Metal detecting for surveying marching camps?”. Limes XXII, Proceedings of the 22nd International Congress of Roman Frontier Studies. Ruse, Bulgaria, September 2012: 853-860.

Pérez Daza, F. (2003): "Nueva aportación al estudio del armamento ibérico en la línea Almedinilla-Porcuna-Andújar". Antiquitas, 15: 59-64.

Prats Darder, C.; Rovira Hortalà, M. C. y Miró Segura, J. H. (1996): “La falcata i la beina damasquinades trobades a la tomba 53 de la necròpoli ibèrica de la Serreta d'Alcoi. Procés de conservació-restauració i estudi tecnològic". Recerques del Museu d'Alcoi, 5: 137-154.

Quesada Sanz, F. (1988): "Las acanaladuras en las hojas de falcatas ibéricas". Cuadernos de Prehistoria y Arqueología, 15: 275-299. http://dx.doi.org/10.15366/cupauam1988.15.009

Quesada Sanz, F. (1989): Armamento, guerra y sociedad en la necrópolis ibérica de El Cabecico del Tesoro (Murcia, España). Oxford, Archaeopress.

Quesada Sanz, F. (1992): Arma y símbolo: la falcata ibérica. Alicante, Instituto de Cultura Juan Gil-Albert.

Quesada Sanz, F. (1993): "Soliferrea de la Edad del Hierro en la Península Ibérica”. Trabajos de Prehistoria, 50: 159-183. http://dx.doi.org/10.3989/tp.1993.v50.i0.495

Quesada Sanz, F. (1997): El armamento ibérico. Estudio tipológico, geográfico, funcional, social y simbólico de las armas en la cultura ibérica (siglos VII-I a. C.). Montagnac, Mergoil.

Quesada Sanz, F. (1998): "El guerrero y sus armas". Boletín de la Asociación Española de Amigos de la Arqueología 38: 187-218.

Quesada Sanz, F. (2002a): "La evolución de la panoplia. Modos de combate y tácticas de los iberos". Moret, P. y Quesada, F. (eds.), La guerra en el mundo ibérico y celtibérico (ss. VI-II a. C.). Madrid, Casa de Velázquez: 35-64.

Quesada Sanz, F. (2002b): “Armas y arreos de caballo en la protohistoria peninsular. Problemas de la documentación y líneas de investigación prioritarias". Moret, P. y Quesada Sanz, F. (eds.), La guerra en el mundo Ibérico y Celtibérico (ss. VI-II a. de C.). Madrid, Casa de Velázquez: 1-34.

Quesada Sanz, F. (2002-2003): "Mirando el mundo desde lo alto: espuelas y otros elementos asociados al caballo en el poblado de La Serreta de Alcoi". Recerques del Museu d'Alcoi 11-12:85-100.

Quesada Sanz, F. (2004): "Armamento indígena y romano republicano en Iberia (ss. III-I a. C.). Compatibilidad y abastecimiento de las legiones republicanas en campaña". II Congreso de Arqueología 
Militar Romana en Hispania. Producción y abastecimiento en el ámbito militar. León, Universidad de León: 75-96.

Quesada Sanz, F. (2005): "El guerrero ibérico a través de El Cigarralejo". El Museo de Arte Ibérico de El Cigarralejo. Murcia, Dirección General de Cultura: 111-134.

Quesada Sanz, F. (2009): "La guerra en la Cultura Ibérica". Almagro, M. (coord.), Historia militar de España. Prehistoria y Antigüedad. Madrid, Ministerio de Defensa: 111-130.

Quesada Sanz, F. (2010a): Armas de la Antigua Iberia: de Tartessos a Numancia. Madrid, La esfera de los libros.

Quesada Sanz, F. (2010b): "Las armas en los poblados ibéricos: teoría, método y resultados". Dossier De armas, de hombres y de dioses. El papel de las armas en la conquista romana de la Península Ibérica, Gladius, 30: 17-42. http://dx.doi.org/10.3989/gladius.2010.0001

Quesada Sanz, F. (2010-2012): "Perspectivas sobre la conservación, restauración e investigación de las armas antiguas. Desiderata de un arqueólogo e historiador militar". Sautuola, 16-17: 381-387.

Quesada Sanz, F. (2014): "Novedades y líneas de investigación recientes en la arqueología militar de la Iberia Prerromana. Una aproximación bibliográfica". Martínez Ruiz, E.; Cantera Montenegro, J. (dirs.), Perspectivas y novedades de la Historia Militar. Una aproximación global. Madrid, Ministerio de Defensa: 59-92.

Reig, C. (2000): "El armamento de la necrópolis ibérica de La Serreta de Alcoi (Alicante, España)". Gladius, 20: 75-117. http://dx.doi.org/10.3989/gladius.2000.65

Rovira, S. (2004): "Metalurgia celtibérica: estado de la cuestión y nuevas perspectivas". Barril, M.; Rodero, A. (eds.), Novedades arqueológicas celtibéricas. Madrid, Ministerio de Cultura: 63-84.

Rovira Hortalà, M. C. (1998): "Les premiers objects de fer en Catalogne (VIIe-VIe s. av. N. ère)". Feugère, M. y Serneels, V. (eds.), Recherches sur l'économie du fer en Méditerranée nord-occidentale. Montagnac, Mergoil: 45-55.

Rovira Hortalà, M. C. (2000): "Los talleres de herrero en el mundo ibérico: aspectos técnicos y sociales". Saguntum: Papeles del Laboratorio de Arqueología de Valencia, extra 3, Ibers. Agricultors, artesans i comerciants, III ${ }^{a}$ Reunió sobre Economia en el Món Ibèric. Valencia, SIP: 265-270.

Rovira Llorens, S. (1993): "La metalurgia de la Edad del Hierro en la Península ibérica". Arana, R.; Muñoz, A. M.; Ramallo, S. y Ros, M. (eds.), Metalurgia en la Península Ibérica durante el primer milenio a. C. Estado actual de la investigación. Murcia, Universidad de Murcia: 45-70.

Rovira Llorens, S.; Montero Ruiz, I. y Consuegra Rodríguez, S. (1997): Las primeras etapas metalúrgicas en la Península Ibérica I: análisis de materiales. Madrid, Instituto Universitario Ortega y Gasset.

Rovira Llorens, S. (2000): "Continuismo e innovación en la metalurgia ibérica". Saguntum: Papeles del Laboratorio de Arqueología de Valencia, extra 3, Ibers. Agricultors, artesans i comerciants, III ${ }^{a}$ Reunió sobre Economia en el Món Ibèric.Valencia, SIP: 209-227.

Rovira Llorens, S. y Gómez Ramos, P. (2003): Las primeras etapas metalúrgicas en la Península Ibérica III: Estudios Metalográficos. Madrid, Salvador Rovira Llorens.

Sanz Gamo, R. (1997): Cultura ibérica y romanización en tierras de Albacete: los siglos de transición. Albacete, Instituto de Estudios Albacetenses.

Sanz Mínguez, C. (2008): "Un puñal-reliquia vacceo hallado en Pintia (Padilla de Duero, Valladolid)", Gladius, 28: 177-194. http://dx.doi.org/10.3989/gladius.2008.195

Scott, D. A. (1991): Metallography and microstructure of ancient and historic metals. Marina del Rey, Getty Conservation Institute and Archetype Books.

Soria, L. (2000): La cultura ibérica en la provincia de Albacete. Génesis y evolución a través del estudio del poblamiento. Tesis doctoral, Cuenca, Universidad de Castilla-La Mancha.

Vives-Ferrándiz Sánchez, J.; Iborra Eres, P.; Bonet Rosado, H.; Pérez Jordà, G.; Carrión Marco, Y.; Quesada Sanz, F.; Ferrer García, C. y Tortajada Comeche, G. (2015): "Ofrendas para una entrada: Un depósito ritual en la Puerta Oeste de la Bastida de les Alcusses (Moixent, Valencia)". Trabajos de Prehistoria, 72 (2): 282-303. http://dx.doi.org/10.3989/tp.2015.12155 